Please do not remove this page

RMIT

UNIVERSITY

\title{
A finite element methodology for analysing degradation and collapse in postbuckling composite aerospace structures
}

Orifici, Adrian; Thomson, Rodney; Degenhardt, Richard; Bisagni, Chiara; Bayandor, Javid https://researchrepository.rmit.edu.au/esploro/outputs/9921857777701341/filesAndLinks?institution=61RMIT_INST\&index=null

Orifici, A., Thomson, R., Degenhardt, R., Bisagni, C., \& Bayandor, J. (2009). A finite element methodology for analysing degradation and collapse in postbuckling composite aerospace structures. Journal of Composite Materials, 43(26), 3239-3263. https://doi.org/10.1177/0021998309345294

Document Version: Accepted Manuscript

Published Version: https://doi.org/10.1177/0021998309345294

Repository homepage: https://researchrepository.rmit.edu.au

(C) The Author(s)

Downloaded On 2023/04/26 23:06:48 +1000 
Thank you for downloading this document from the RMIT Research Repository.

The RMIT Research Repository is an open access database showcasing the research outputs of RMIT University researchers.

RMIT Research Repository: http://researchbank.rmit.edu.au/

\section{Citation:}

Orifici, A 2009, 'A finite element methodology for analysing degradation and collapse in postbuckling composite aerospace structures', Journal of Composite Materials, vol. 43, no. 26, pp. 1-26.

See this record in the RMIT Research Repository at:

http://researchbank.rmit.edu.au/view/rmit:5970

Version: Accepted Manuscript

Copyright Statement: (c) The Author(s)

Link to Published Version:

http://dx.doi.org/10.1177/0021998309345294 


\title{
A Finite Element Methodology for Analysing Degradation and Collapse in Postbuckling Composite Aerospace Structures
}

\author{
Adrian C. Orifici ${ }^{1,2,}{ }^{*}$, Rodney S. Thomson ${ }^{2}$, Richard Degenhardt ${ }^{3}$, Chiara Bisagni ${ }^{4}$, \\ Javid Bayandor ${ }^{5}$ \\ ${ }^{1}$ School of Aerospace, Mechanical and Manufacturing Engineering, \\ Royal Melbourne Institute of Technology \\ GPO Box 2476V, Melbourne, Victoria 3001, Australia \\ ${ }^{2}$ Cooperative Research Centre for Advanced Composite Structures \\ 506 Lorimer Street, Fishermans Bend, Victoria, 3207, Australia \\ ${ }^{3}$ Institute of Composite Structures and Adaptive Systems, DLR - German Aerospace Center \\ Lilienthalplatz 7, 38108 Braunschweig, Germany \\ ${ }^{4}$ Dipartimento di Ingegneria Aerospaziale, Politecnico di Milano, \\ Via La Masa 34, 20156 Milan, Italy \\ ${ }^{5}$ The Sir Lawrence Wackett Aerospace Centre \\ School of Aerospace, Mechanical and Manufacturing Engineering, Royal Melbourne Institute of Technology \\ GPO Box 2476V, Melbourne, Victoria 3001, Australia
}

\begin{abstract}
A methodology for analysing the degradation and collapse in postbuckling composite structures is proposed. One aspect of the methodology predicts the initiation of interlaminar damage using a strength criterion applied with a global-local analysis technique. A separate approach represents the growth of a pre-existing interlaminar damage region with user-defined multi-point constraints that are controlled based on the Virtual Crack Closure Technique. Another aspect of the approach is a degradation model for in-plane ply damage mechanisms of fibre fracture, matrix cracking and fibre-matrix shear. The complete analysis methodology was compared to experimental results for two fuselage-representative composite panels tested to collapse. For both panels, the behaviour and structural collapse were accurately captured, and the analysis methodology provided detailed information on the development and interaction of the various damage mechanisms.
\end{abstract}

KEY WORDS: Stiffened structures, Postbuckling, Collapse, Interlaminar damage, Ply damage, Virtual Crack Closure Technique.

\section{INTRODUCTION}

In the aerospace industry, the application of lightweight fibre-reinforced polymer materials and the use of "postbuckling" skin-stiffened structures to withstand immense loads after buckling are key technologies that have separately been used to significantly improve structural efficiency. However, to date the application of composite postbuckling structures in aircraft designs has been limited, due to concerns related to both the durability of composite structures and the accuracy of design tools. For undamaged skin-stiffened structures in compression, collapse is typically an explosive event caused by the initiation of separation between the skin and stiffener. For pre-damaged structures, such as those taken from service or those used for damage tolerance and certification studies, the pre-damaged areas can grow under compression and contribute to structural collapse. Collapse for both of these

\footnotetext{
* Corresponding author: A. Orifici, CRC-ACS, 506 Lorimer Street, Fishermans Bend, Victoria 3207, Australia. a.orifici@.crc-acs.com.au, phone +61 39676 4905, fax +61 396764999.
} 
configurations is typically characterised by rapid fibre fracture, particularly in the stiffeners, which causes a significant loss of load-carrying capacity.

In this work, a finite element (FE) analysis methodology was developed and implemented into MSC.Marc (Marc) in order to predict the collapse of skin-stiffened structures taking degradation into account. One aspect of this methodology is a strength-based approach for analysing undamaged or intact structures that uses a global-local technique. Another aspect is a degradation model that applies user-defined MPCs controlled by fracture mechanics to represent interlaminar damage growth. In-plane ply damage is also modelled using a progressive failure approach that is based on strength-based failure criteria and corresponding reduction of ply stiffness.

Following a description of the developed analysis methodology, experimental results are presented for two large, blade-stiffened panels that are representative of composite fuselage designs. The panels had different skin lay-ups and geometry definitions, and one panel was loaded statically until collapse as an undamaged structure, whilst the other was first loaded cyclically into the postbuckling region, which generated regions of skin-stiffener debonding prior to a static loading to collapse. Numerical models were created using the developed methodology and are shown to give very good comparison with the experimental results, with the panel behaviour, load-carrying capacity and collapse damage mechanisms accurately captured in both cases. Discussion is then given on the possible extension of the developed methodology, and its application for advanced analysis of the key damage mechanisms in composite skin-stiffened structures.

This work is part of the European Commission Project COCOMAT, a four-year project to exploit the large strength reserves of composite aerospace structures through a more accurate prediction of collapse [1-2].

\section{COLLAPSE OF COMPOSITE AEROSPACE STRUCTURES}

Lightweight construction in the aerospace industry is characterised by thin skins periodically reinforced with stiffening members, which are located lengthwise along the direction of the main compression load, and spanwise across the width of the main compression load. Under compression, composite aerospace structures experience buckling and develop a range of damage mechanisms, which under further loading combine and lead to the eventual collapse of the structure in the postbuckling region. For undamaged skin-stiffened structures collapse is typically an explosive event caused by the initiation of separation between the skin and stiffener. For pre-damaged structures, such as those taken from service or those used for damage tolerance and certification studies, the pre-damaged areas can grow under compression and contribute to structural collapse [3-5]. The critical phenomena and damage mechanisms for collapse include buckling and postbuckling, fibre failure, delamination, skinstiffener debonding, matrix cracking and fibre-matrix shear.

Structures loaded in compression typically undergo buckling, which involves the structure deforming into a minimum potential energy deformation configuration. Under further compression into the postbuckling region, the buckling deformation pattern or mode shape can change, as the structure adopts new configurations to minimise energy. The development and progression of buckling mode shapes is a fundamental feature of compression-loaded structures, and accurate mode shape capturing is critical to successfully representing all aspects of structural deformation. In aerospace structures, buckling patterns are generally a 
combination of global buckling waves between the lengthwise stiffeners and local buckling waves between the spanwise stiffeners.

The development of in-plane ply damage mechanisms is also critical to the collapse of composite structures. Fibre failure is the principal damage mechanisms causing collapse, and is critical to identify and quantify in any analysis. In fibre-reinforced composites the fibres act as the principal load-bearing constituents, and resist the majority of the applied loads. The failure of any fibres causes a redistribution of loads to the surrounding region that generally promotes further failure, so that the onset of fibre failure typically leads to almost instantaneous structural collapse in the absence of alternative load paths. Other ply damage mechanisms such as matrix cracking and fibre-matrix shear are also important to capture, and generally occur at several locations throughout the laminate and result in local ply softening and stress redistribution. Though matrix cracking and fibre-matrix shear as individual damage modes do not result in significant loss of load-carrying capacity, the local softening can have important effects on the panel deformation and buckling mode, and can influence the development of other damage mechanisms.

Interlaminar damage in one of the critical damage mechanisms for laminated composite materials in general, and is especially crucial for compression-loaded structures as it results in the formation of substructures that buckle, separate and lead to collapse. Delamination is the most common form of interlaminar damage, and occurs due to high through-thickness stresses overcoming the interlaminar bond strength between two plies. For composite aerospace structures, the skin and stiffeners are either co-cured as a complete laminate or manufactured separately and adhesively bonded. As a result, interlaminar damage for aerospace structures is most commonly encountered as skin-stiffener debonding, either as delaminations at or around the skin-stiffener interface in co-cured laminates, or as adhesive failure in secondary bonded structures. Skin-stiffener debonding is a common, and often explosive, form of failure, which has occurred in a large number of experimental investigations into postbuckling stiffened structures.

\section{ANALYSIS METHODOLOGY}

An analysis methodology was developed to predict the collapse of stiffened composite structures in compression that is focused on capturing the effects of the critical damage mechanisms. The approach contains several aspects: predicting the initiation of interlaminar damage in intact structures; capturing in-plane degradation such as fibre fracture and matrix cracking; capturing the propagation of a pre-existing interlaminar damage region [7-8].

\section{Interlaminar Damage Initiation}

The approach for predicting the initiation of interlaminar damage in the skin-stiffener interface was based on a two-step global-local technique. This approach is illustrated in Figure 1, and has been presented previously [9]. In this approach, a coarse model of the entire structure was constructed using computationally efficient shell elements, and combined with local models of the skin-stiffener interface cross-section that used three-dimensional (3D) solid brick elements. This combination is highly suited for the analysis of large aerospace structures, as it allows the through-thickness stress distribution to be analysed at any number of locations throughout the structure, without requiring a complete 3D model of the entire structure or the complicated constraint conditions of a hybrid 2D-3D model. 


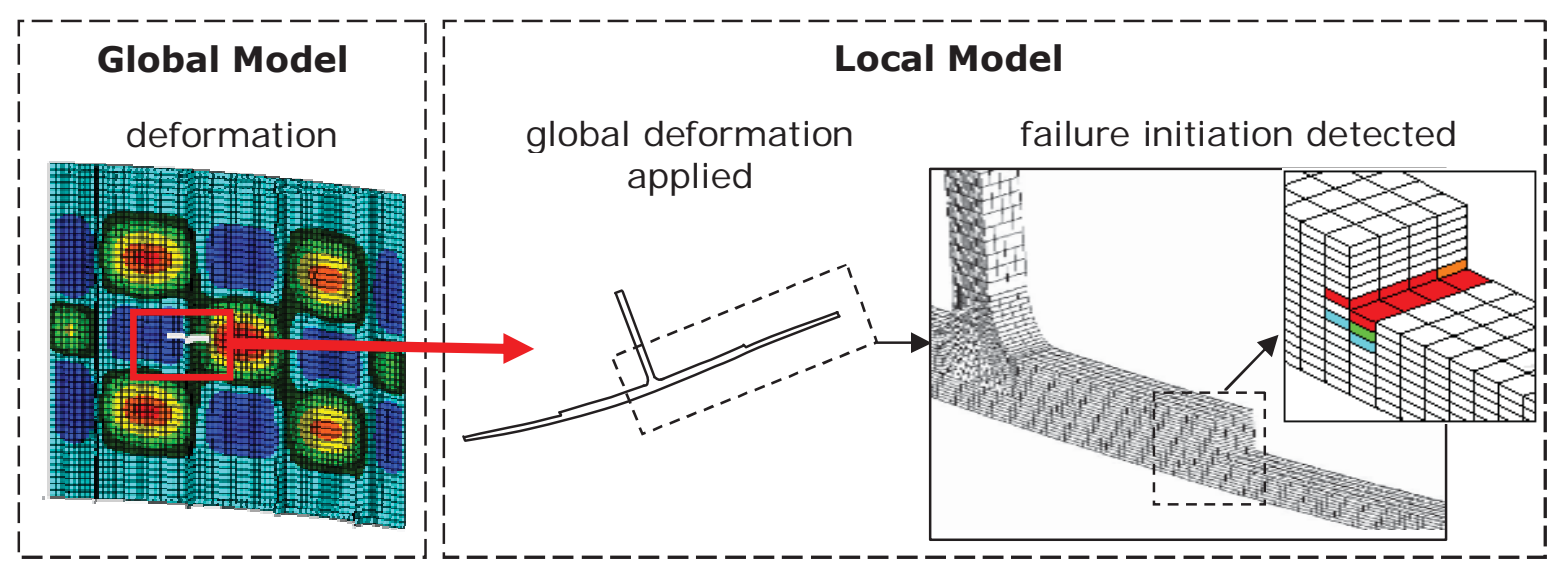

Figure 1: Global-local approach for detecting skin-stiffener delamination initiation

In the approach, the global shell model was used to determine the deformation field of the entire structure, which was then input as boundary conditions on a local 3D model of a skinstiffener interface. In the local model a strength criterion was monitored at all elements in order to predict the initiation of delamination or skin-stiffener separation. The criterion applied was the "degenerated Tsai" equation as given by Tong [10] and was defined as

$$
\left(\sigma_{\mathrm{x}} / X_{\mathrm{T}}\right)^{2}+\left(\sigma_{\mathrm{z}} / Z_{\mathrm{T}}\right)^{2}+\left(\tau_{\mathrm{yz}} / S_{\mathrm{yz}}\right)^{2} \geq 1
$$

where $\sigma_{\mathrm{x}}, \sigma_{\mathrm{z}}, \tau_{\mathrm{yz}}$ and $X_{\mathrm{T}}, Z_{\mathrm{T}}, S_{\mathrm{yz}}$ are stresses and strengths in the longitudinal, throughthickness tensile and shear directions, respectively. The longitudinal stress is included in this equation as it was found to influence delamination initiation in composite joints, particularly for plies adjacent to an adhesive layer [10]. Failure was deemed to occur when the average of all integration point values in an element satisfied this criterion. By modifying the location of the 3D local model, the initiation of interlaminar damage throughout the panel could be investigated in order to determine the most critical skin-stiffener interface location. The prediction of delamination in local skin-stiffener interfaces using this approach has been successfully demonstrated previously [11-12].

\section{Ply Damage Model}

For the ply damage degradation model, an approach was developed for capturing in-plane damage occurring within the plies of the composite material. The development of failure theories for composite materials has been an active area of research for over 30 years and there are numerous approaches available in the literature. For failure criteria, there is a clear difference between fully interactive criteria like Tsai-Wu [13], which represent general lamina failure using a single criterion, and criteria that distinguish between the different ply failure modes. Though there continues to be considerable debate between the two approaches (see for example, the failure exercise in Reference [14]), the failure-mode based criteria are generally considered more suitable, particularly for degradation models, due to the additional information provided by the consideration of the separate failure mechanisms.

In terms of the failure mechanisms considered, fibre-reinforced composite plies can display failure in the fibre and matrix, with separate mechanisms in tension, compression and shear. For fibres, tensile failure occurs due to the accumulation of individual fibres failing in tension, and is commonly predicted with simple limit-based equations using tensile strength parameters from experimental coupon tests. Fibres in compression fail due to microbuckling of the fibres, and though some authors have developed criteria and approaches for handling 
this phenomenon, simple strength-based limit equations are still commonly applied [14]. Failure under in-plane shear occurs along the fibre-matrix interfaces, and though no consistent approach has been applied, Hashin [15] proposed a quadratic interactive criterion that combines longitudinal and in-plane shear stresses. Matrix failure is complex, where cracking typically initiates at defects or fibre-matrix interfaces, and failure occurs at the critical fracture plane through the matrix, which is dependent on the combination of loads acting on the material [16]. Though a considerable amount of development on this subject is available in the literature, for example in the identification of the critical failure plane angle and a number of different matrix failure modes [16-17], or the application of in-situ material strengths and incorporation of fracture mechanics considerations [18], the criteria of Hashin have shown a reasonable degree of accuracy in all loading conditions, and continue to be widely applied $[14,18-19]$.

On the basis on these considerations, an approach based on the Hashin [15] failure criteria and stiffness reduction method of Chang and Lessard [20] was used, as summarised in Table 1, where $\sigma_{11}, \sigma_{22}, \tau_{12}$ and $X, Y, S_{12}$ are stresses and strengths in the fibre, in-plane transverse and shear directions, $S_{23}$ is the through-thickness shear strength (assumed equal to $S_{12}$ for a transversely isotropic ply), and subscripts $T$ and $C$ refer to tension and compression. The criteria for fibre failure, matrix cracking and fibre-matrix shear failure were monitored and used to reduce the appropriate material properties to zero upon detection of failure. The failure criteria given in Table 1 were used to define three binary failure indices, $f, m$ and $s$ at every element integration point, which were given a value of 1 upon detection of fibre, matrix or fibre-matrix shear failure, respectively. These binary indices were combined to give a single index for in-plane failure as shown in Table 2.

\section{Interlaminar Damage Growth}

In the interlaminar damage growth model [21-22], pre-existing interlaminar damage in the skin-stiffener interface was represented as a debonded region between the skin and stiffener. Nominally coincident shell layers were connected with user-defined multi-point constraints (MPCs). The user-defined MPCs were given one of three "states", which were used to define the intact (state 0), crack front (state 1) and debonded (state 2) regions as shown in Figure 2. Gap elements were used in any debonded region to prevent crossover of the two sublaminates.

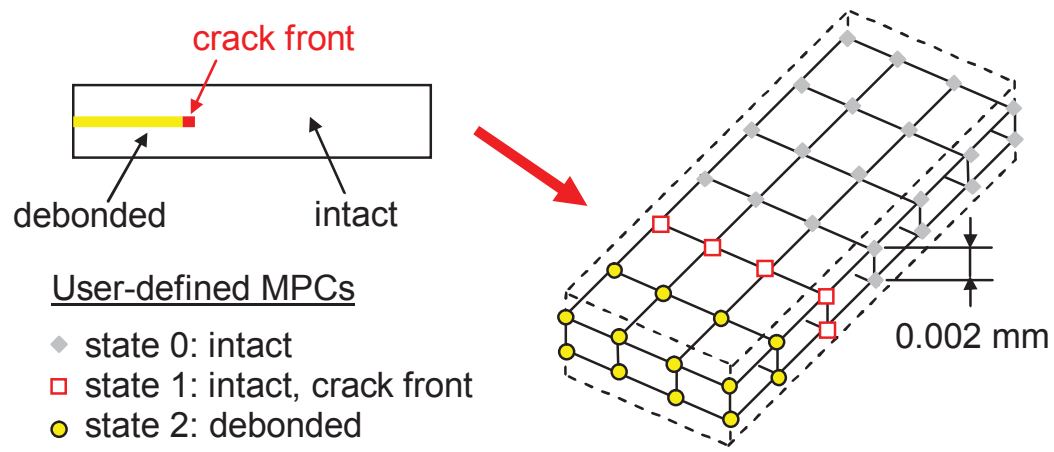

Figure 2: Interlaminar damage modelling with user-defined MPCs.

At the end of every nonlinear analysis increment, the Virtual Crack Closure Technique (VCCT) [23] was used to determine the strain energy release rates at all MPCs on the crack front. The VCCT equations accounted for arbitrary element sizes, and an algorithm was written to determine the local crack front coordinate system from the neighbouring crack front nodes, following recommendations given in Reference [24]. The onset of propagation was 
determined using the B-K criterion [25], with modification for the inclusion of the mode III component following the suggestion given in Reference [26], given by

$$
\frac{\left(G_{I}+G_{I I}+G_{I I I}\right)}{\left(G_{I C}+\left(G_{I I C}-G_{I C}\right)\left[\left(G_{I I}+G_{I I I}\right) /\left(G_{I}+G_{I I}+G_{I I I}\right)\right]^{\eta}\right)}=1,
$$

where $G$ are the strain energy release rates in modes I, II and III, $G_{C}$ are fracture toughness values, and $\eta$ is a curve fit parameter found from mixed-mode test data. For crack propagation, an iterative method was applied, which was defined as follows:

1. At the end of every increment, the VCCT with Equation (2) was used to determine the set of crack front nodes at which crack growth or "failure" was deemed to occur.

2. The values of $G_{I}, G_{I I}$ and $G_{I I I}$ were reduced based on the shape of local crack front to be created upon release of failing MPCs. This reduction is described in greater detail below.

3. Equation (2) was used again with the reduced strain energy release rates, to determine a new set of failing MPCs.

4. Steps 2 and 3 were repeated until a consistent set of failing MPCs (or no MPCs were found to fail) using the reduced strain energy release rates.

5. Any failing crack front MPCs were then "released" or set from state 1 to state 2 for the start of the next increment.

The iterative method was an extension of the simple "fail-release" approach, which would consist of only Steps 1 and 5 as given above. The reductions in the strain energy release rate in Step 2 were necessary as it has been found that the strain energy released in propagation is dependent on the shape of the local crack front created upon crack growth. This affects the VCCT assumption that crack growth occurs in a self-similar manner, which can be violated when crack propagation is performed arbitrarily. Critically, this means that the fail-release approach, which is the method most commonly combined with VCCT to model crack propagation, can lead to significant over-estimation of the strain energy release rates, particularly in mode I crack opening. The iterative propagation method has been demonstrated in both single mode and mixed-mode investigations to give more realistic estimations of the strain energy released in crack growth than a simple fail-release approach [21-22].

Step 2 of the iterative process described above applied modification factors to the strain energy release rates to account for the difference in crack opening between the actual crack propagation and the assumed self-similar case. These factors were determined previously from extensive parametric studies involving two-step crack growth scenarios. From these, it was found that the crack opening displacement could be related to the shape of the local crack front, which was taken to consist of the MPC under consideration and the MPCs directly connected to it via only one element boundary. A lookup table of conservative modification factors was created for each mode, and for different local crack front patterns. More detail on this process can be found in the previous publications [21-22].

In the analysis applied in this work, the interlaminar damage is modelled at the skin-stiffener interface. Though interlaminar damage can theoretically occur between any interface throughout the laminate, the skin-stiffener interface was selected to represent all structural degradation due to interlaminar damage, for a number of reasons: 
- Many researchers experimentally investigating postbuckling composite structures have concluded that skin-stiffener debonding is a critical damage type (see for example [3-5]). Locating the interface element layer at the skin-stiffener interface allows direct control of the properties of this crucial connection.

- In experiments, the stress concentrations at the geometry change between the stiffener flange and skin and the different bending properties of the two structural elements typically result in debonding initiation at or very close to the stiffener interface.

- In experiments of skin-stiffened structures, debonds that initiate at the skin-stiffener interface typically migrate at some stage to other ply interfaces in the vicinity, and have even resulted in multiple cracks at several interfaces. However, in general, this type of debonding is centred around the skin-stiffener interface, and modelling a single damage site there would represent a worst-case scenario for crack growth.

One problem with the use of the skin-stiffener interface is the issue of accurate and representative material properties at this location. Material characterisation tests for the strength and toughness of composite materials are usually performed at an interface between two ply layers, or a ply-ply interface. This is appropriate when the skin and stiffener are cocured, as this creates a ply-ply interface between the skin and stiffener. However, standardised fracture mechanics tests are all for characterisation of a $0^{\circ}-0^{\circ}$ interface in a uni-directional laminate, whereas typical aerospace skin-stiffener interface would commonly involve plies at different angles. Whilst an interface between two plies with the same orientation is generally accepted as having a lower fracture toughness than an off-angle interface [27], experimental characterisation of off-angle interfaces are not standardised, and results from testing of multidirectional laminates are not conclusive [28]. Furthermore, for secondary bonded structures the skin-stiffener interface contains an adhesive layer between two plies. The properties of this ply-adhesive-ply of interface are not as well understood, especially with reference to the behaviour of the interface under debonding conditions. Though there are several experimental tests planned within the COCOMAT project to investigate the properties of this type of interface, it is anticipated that the selection of the interface element layer location at the skinstiffener interface will continue to be problematic from a material characterisation point of view. However, as previously noted, material characterisation issues are unavoidably present for any interface.

\section{Overview}

The complete analysis methodology, combining the global-local analysis for interlaminar damage prediction and degradation models for interlaminar damage growth and in-plane damage, was implemented into Marc v2005r3 [6] by a combination of user subroutines [7]. The methodology allows for a complete analysis of the postbuckling and collapse behaviour of composite structure designs, including the effects of damage. The features of the methodology make it suitable in both a design and comparative analysis context for application to both intact and pre-damaged structures.

The methodology is further illustrated in Figure 3, which gives a flow chart of analysis procedures for intact and pre-damaged structures, and the interaction between intact and predamaged models. In general, a global model of the entire structure is first created based on 2D shells. This can be an intact model, or a model containing pre-damage regions, where the predamage is introduced by modifying the initial state of user-defined material or interface properties. An analysis of the global model is conducted, with the global response as output, in addition to ply damage and interlaminar crack growth behaviour if these aspects are included in pre-damaged models. The global results from intact models can then be used with 
local models to analyse the initiation of interlaminar damage, and the local analysis also provides output for the through-thickness stress distribution.

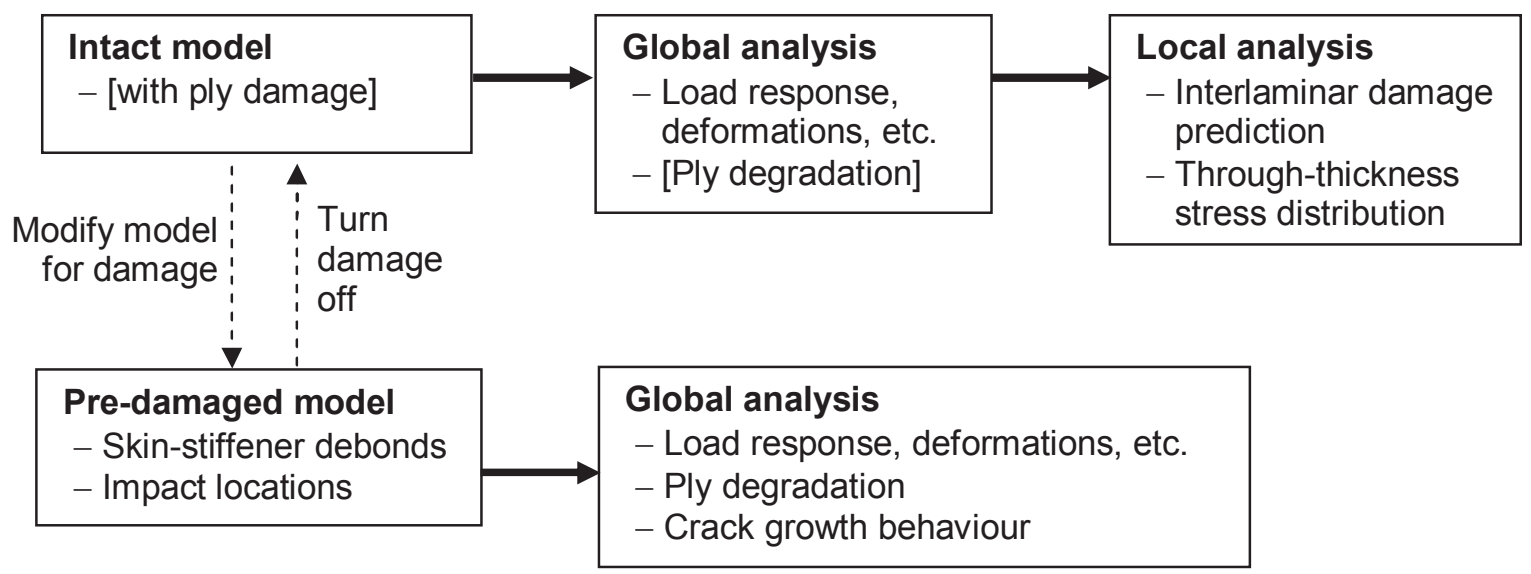

Figure 3: Analysis procedure for intact and pre-damaged models.

\section{EXPERIMENTAL AND NUMERICAL RESULTS}

In this section, results are presented for two multi-stiffener curved panels, representative of composite fuselage designs. The geometry and material lay-up of these panels are given in Table 3 and Figure 4. The panels consisted of a skin and blade-shaped stiffeners, with half the stiffener lay-up on each side used to form flanges and the skin and stiffeners separately cured then bonded with adhesive. Manufacturing the flanges in this manner meant that the 45 degree flange plies were asymmetric about the stiffener blade. The stiffener blade design is illustrated in Figure 5. The two panel designs, labelled D1 and D2, used the same unidirectional (UD) pre-preg tape with different geometry and material lay-ups. The D2 panel was tested in an undamaged (intact) state whilst the D1 panel had pre-damage introduced prior to testing.

Both panels was manufactured by Aernnova Engineering Solutions and tested by the Institute of Composite Structures and Adaptive Systems of DLR (German Aerospace Center) as part of the COCOMAT project. Testing of the panels involved static loading in compression until collapse. A potting consisting of epoxy resin reinforced with sand and quartz was used at the ends of both panels to ensure an even application of the end loadings and prevent lateral movement in the testing machine. The pre-damaged panel used a longitudinal edge restraint to constrain the radial (out-of-plane) displacements along the panel side. 


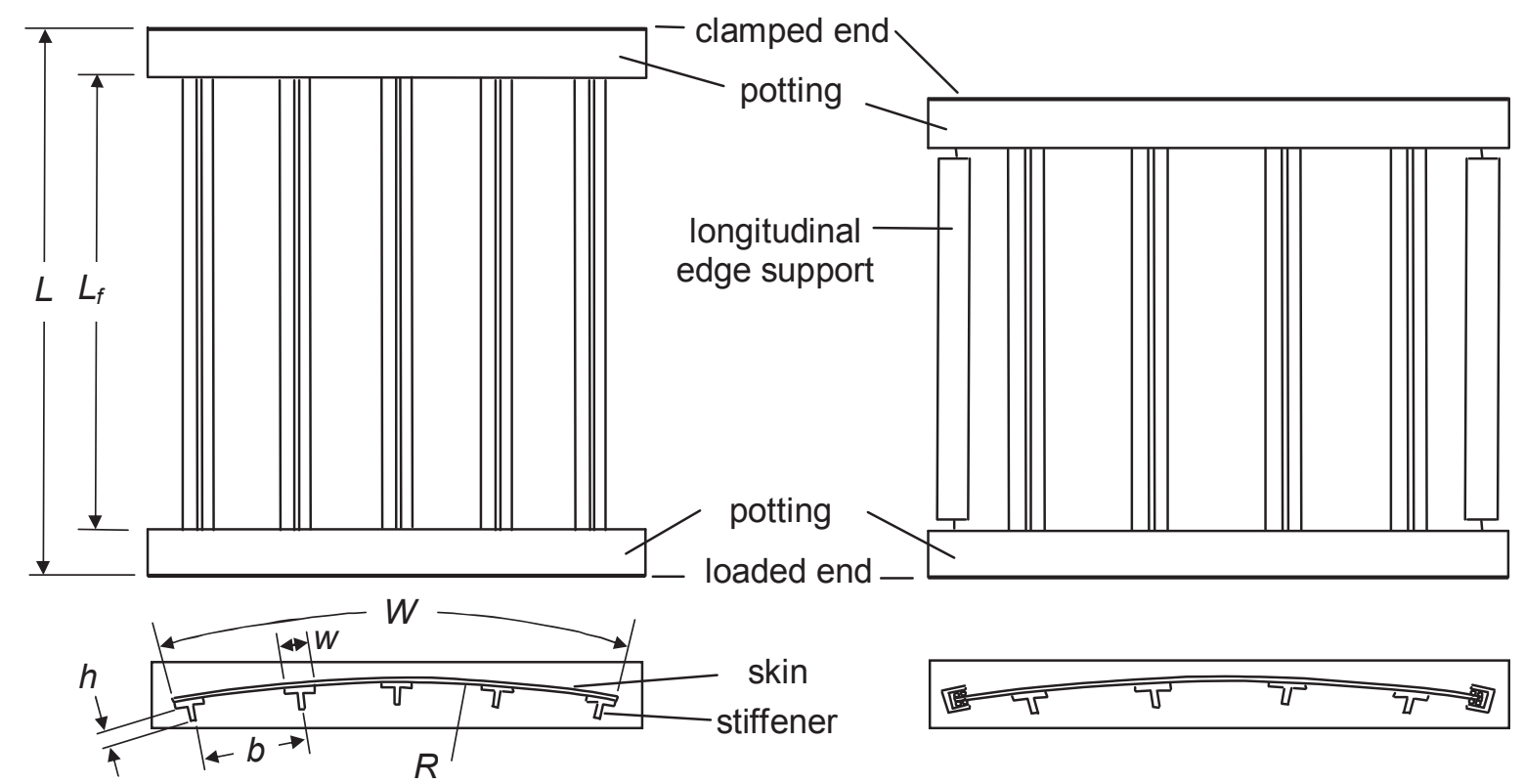

Figure 4: Panel geometry. Left: D1. Right: D2.
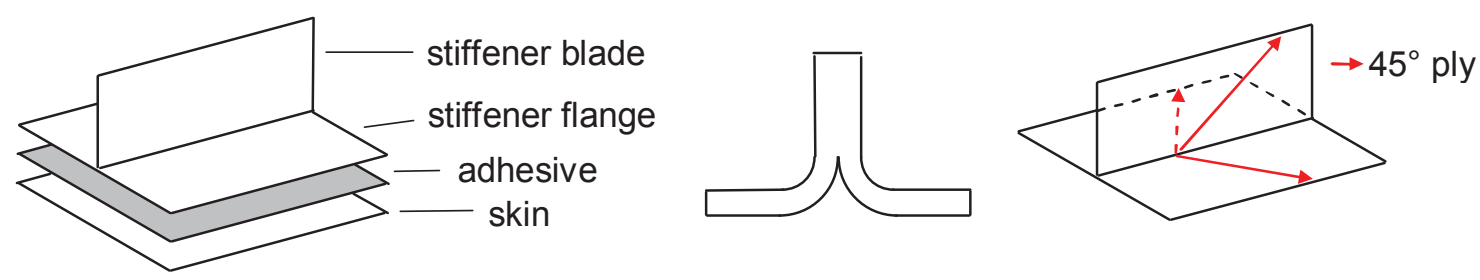

Figure 5: Skin-stiffener joint. Left: Joint components. Middle: Stiffener construction. Right: Joint asymmetry.

Following manufacture, panel quality was inspected with ultrasonic and thermographic scanning. The manufactured geometry of the panel was measured using the $3 \mathrm{D}$ optical measurement system ATOS [29]. In this process, the inside skin surface was measured at a large number of points (500,000 to 1,000,000 is common) and a "cylinder of best fit" found for all points. This cylinder was used to create a cylindrical coordinate system, and the radius of the cylinder was compared to the nominal panel radius. The "imperfection data" was also able to be visualised, and consisted of fringe plots showing radial variation of each point from the best-fit cylinder. This imperfection data was here considered to represent geometrical deviation from the nominal panel geometry as a result of warping during manufacture. Local changes in panel thickness due to varying resin content were not considered. During the test, measurements were taken using displacement transducers (LVDTs), strain gauges, the 3D optical measuring system ARAMIS [29], and optical lock-in thermography. The ARAMIS system applied the same method for determining the cylindrical coordinate system as the ATOS system, and this was used to calculate radial out-of-plane displacements. Further detail on all the inspection and data measurement systems can be found in Reference [30].

\section{Intact Panel (D2)}

The D2 panel was manufactured and inspected according to the specimen details and inspection procedure outlined previously. The ultrasonic and thermographic scans found no damage in the panel after manufacture, and the imperfection data is given in Figure 6. Under compression, the panel developed a range of buckling mode shapes, as shown in Figure 7. Global buckling occurred at $0.47 \mathrm{~mm}$ axial compression and corresponded to one 
buckle in the outer stiffener bays. The buckles were not symmetric, and appeared to be influenced by the imperfection pattern, which showed a region of initial displacement towards the centre of curvature at a panel corner. One of the global buckles was offset from the panel centreline towards this corner, and the bay with this offset buckle developed a second buckle at $0.57 \mathrm{~mm}$ axial compression. Under further compression the panel displayed a range of complex mode shape changes, which included a global buckle in the centre stiffener bay at $0.65 \mathrm{~mm}$, and a second buckle in the other outer stiffener bay at $1.37 \mathrm{~mm}$. During the test, thermographic scans were taken at load levels before and after buckling, and following collapse, though no damage was seen in the panel prior to collapse, shown in Figure 8. Panel collapse occurred at $1.84 \mathrm{~mm}$ axial compression, or $174 \mathrm{kN}$ applied load, and was characterised by fibre fracture in the stiffener and delaminations under all four stiffeners.

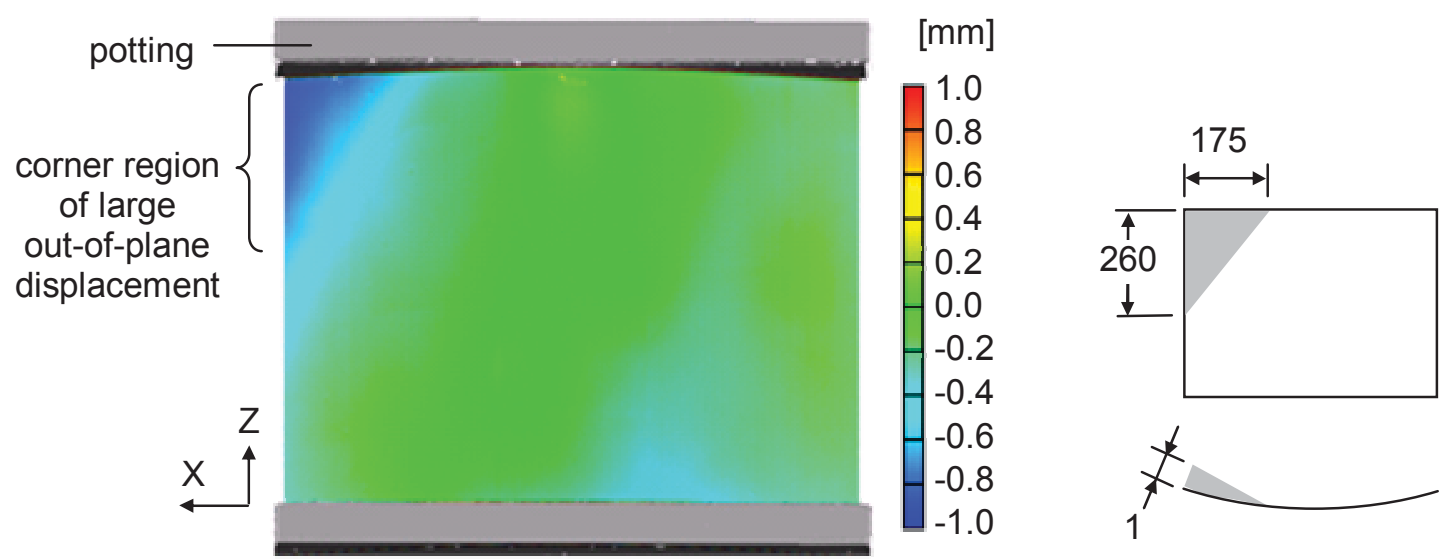

Figure 6: D2 panel imperfection data (skin side). Left: Measured data. Right: Approximated triangular pattern (dimensions in $\mathrm{mm}$ ). 


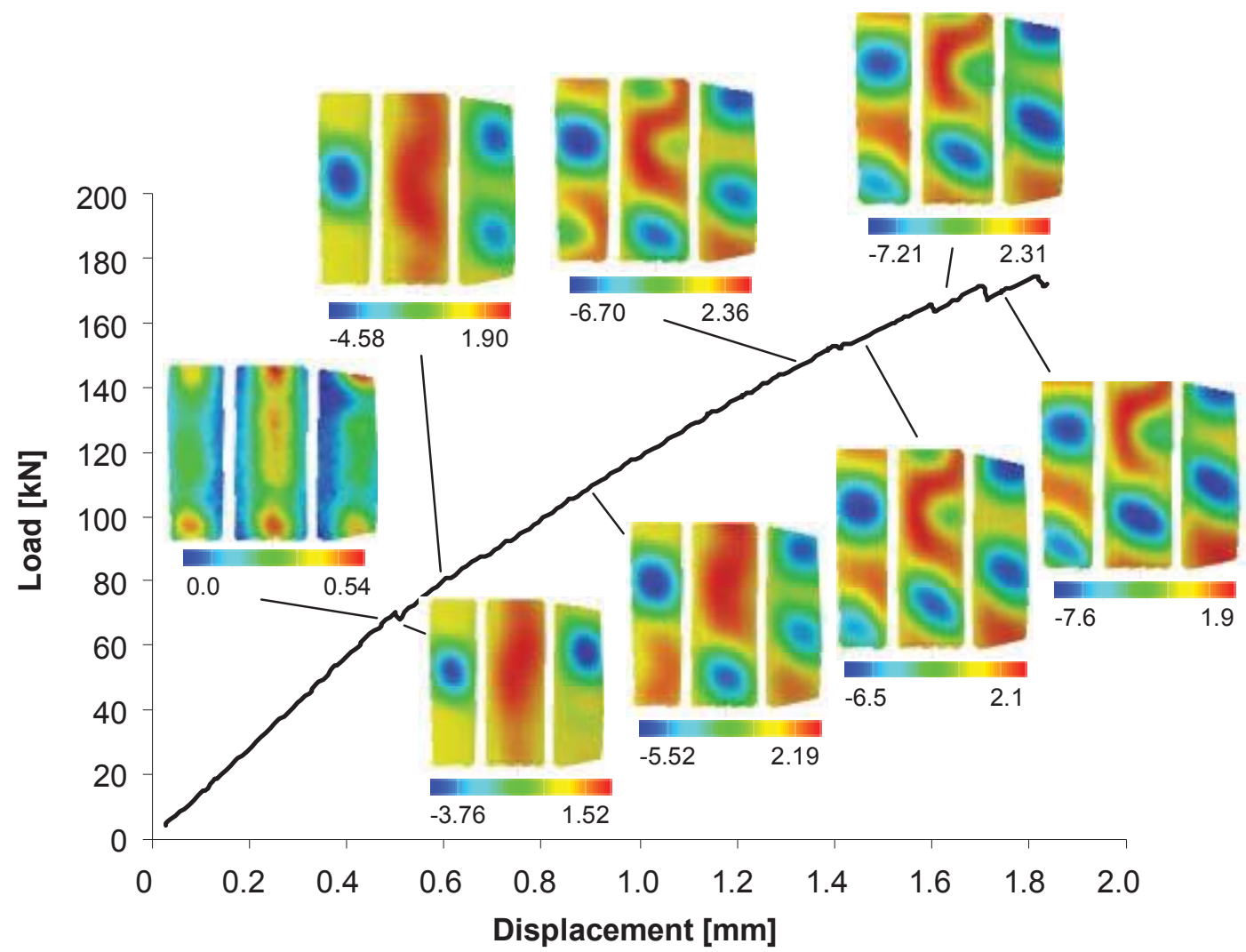

Figure 7: D2 experimental load-shortening, with radial displacement contours (stiffener side).

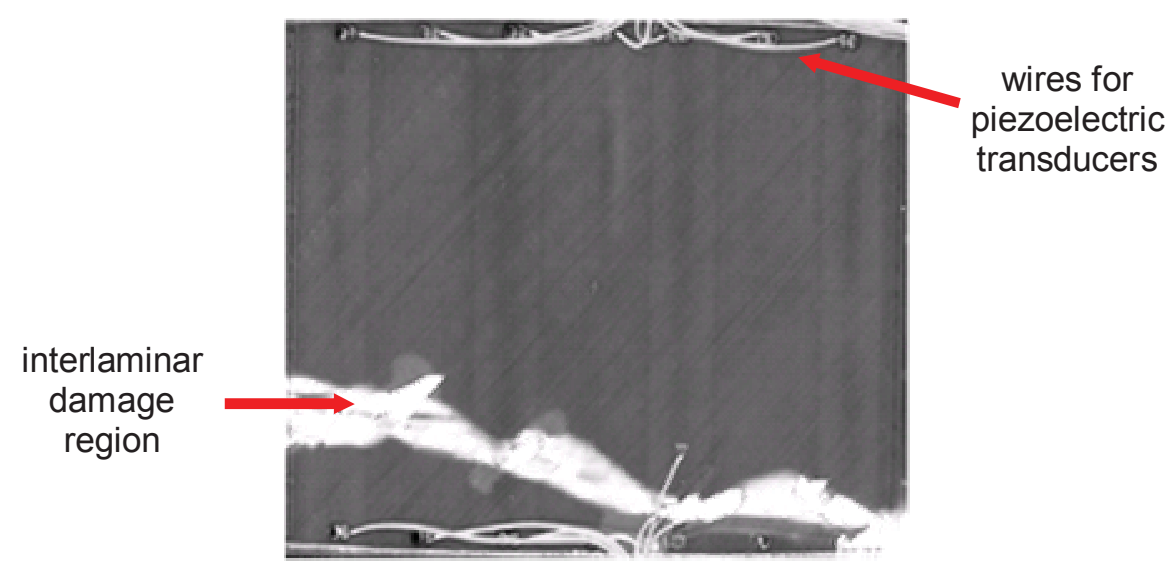

Figure 8: D2 panel thermography scan after collapse (scans taken from the panel skin side).

For the numerical analysis, the global-local analysis technique described previously was applied in order to predict the collapse of the structure by capturing the critical damage mechanisms of fibre fracture and skin-stiffened separation. A global FE model was created using the nominal geometry, and is shown in Figure 9. The nominal global model was modified to create an "imperfect" model to approximate the real geometry of the manufactured panel. To do this the imperfection pattern seen on the left in Figure 6 was approximated by a triangular region with a radial displacement of $1.0 \mathrm{~mm}$ at the panel corner, as shown on the right in Figure 6. Linear interpolation from the $1.0 \mathrm{~mm}$ peak at the corner was used to determine the radial displacement at each node within the triangular region. This approximated imperfection pattern was applied as a displacement in the radial direction, towards the centre of curvature. Though the real panel radius was found from the imperfection measurements to be $1076.5 \mathrm{~mm}$, the nominal and imperfect global models both used the 
nominal value of $1000 \mathrm{~mm}$. The global FE models consisted of 6,413 nodes and 6,032 shell elements, with boundary conditions as shown in Figure 9. Material properties are summarised in Table 4, which were taken from characterisation tests performed by the COCOMAT partners, and the mixed-mode coefficient $\eta$ was taken from data in Refrence [31]. The strength properties were previously presented by Degenhardt et al. [30].

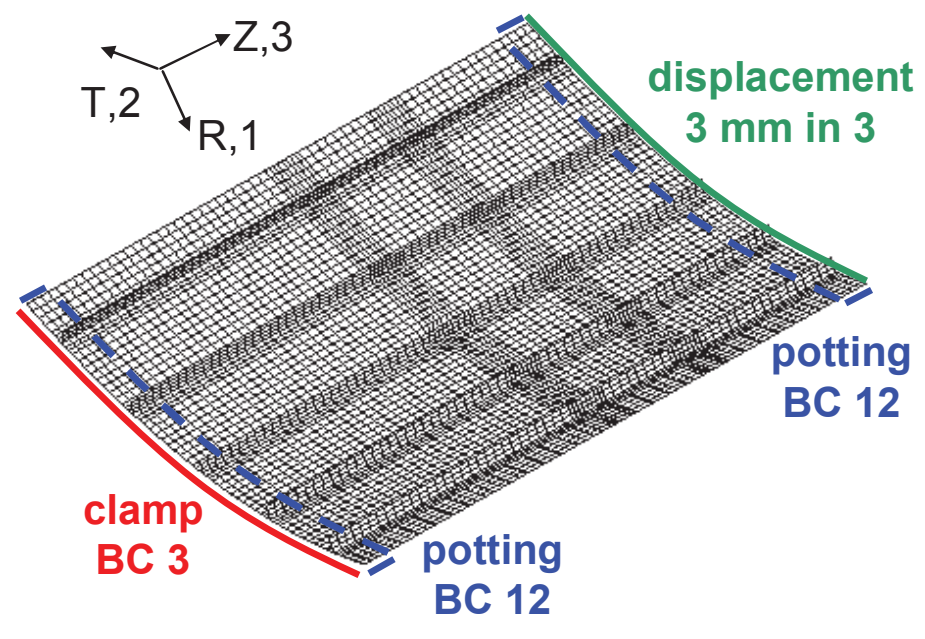

Figure 9: D2 FE model with boundary condition (BC) definition.

A local model was created that consisted of a $4 \mathrm{~mm}$ section of a single skin-stiffener joint, as shown in Figure 10. The model extended from the middle of two panel bays, which corresponded to a circumferential length equal to the stiffener pitch of $156 \mathrm{~mm}$. The local model used a ply-level mesh refinement, as shown in Figure 10 and on the left in Figure 11. This model used eight elements in the longitudinal direction, and consisted of 34,376 nodes and 27,736 solid brick elements. The global-local boundary conditions were applied to 21 nodes on the longitudinal ends of the local model, which corresponded to the node locations of the skin-stiffener interface in the global model shown on the right in Figure 11. The local model with the strength criterion for interlaminar damage was applied at a number of locations throughout the panel, in order to determine the most critical skin-stiffener interface location.

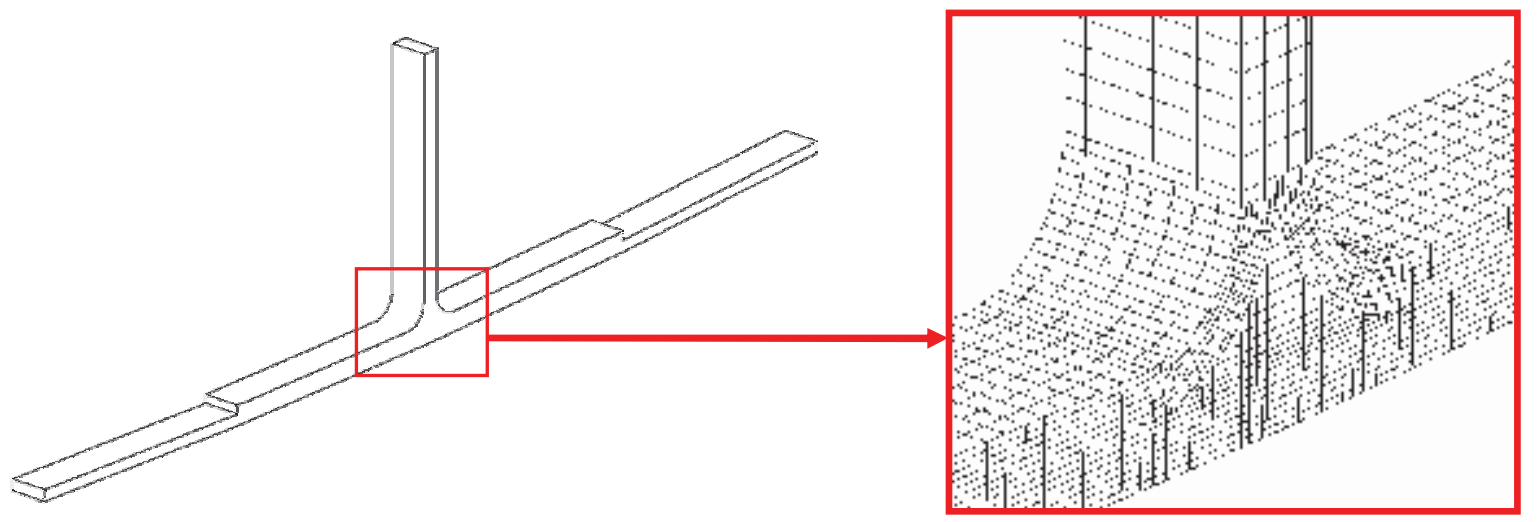

Figure 10: D2 local model. 

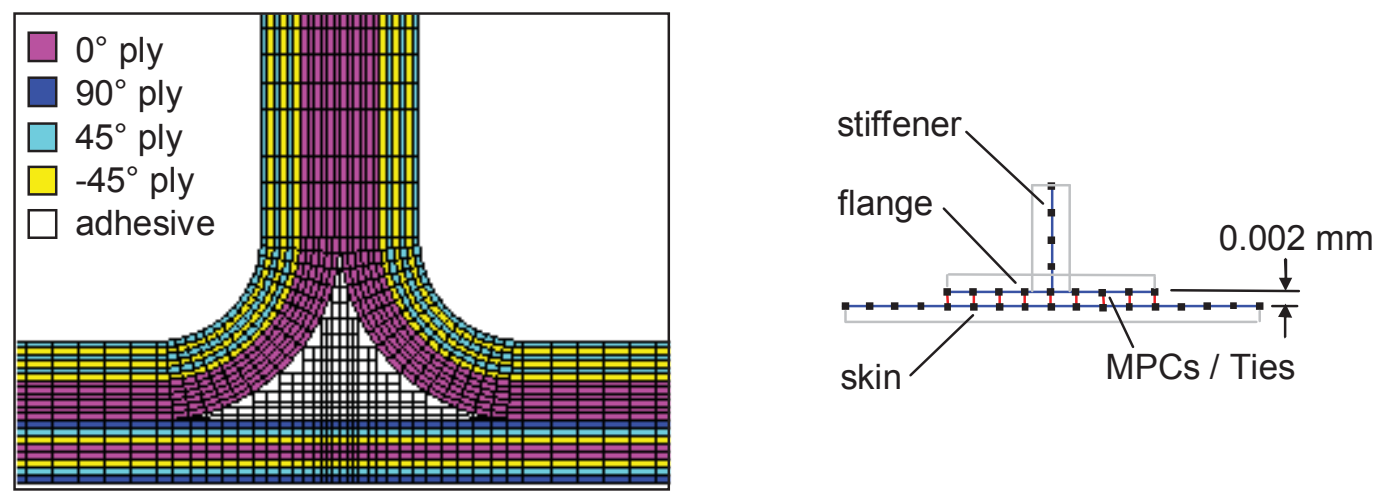

Figure 11: Skin-stiffener interface modelling. Left: Local. Right: Global model.

The models were analysed in Marc v2005r3 using the nonlinear solver with a full NewtonRaphson procedure and a load residuals tolerance of 0.01 [6]. The load-displacement and failure predictions are given in Figure 12 and Figure 13, where debond initiation was predicted to occur at $1.92 \mathrm{~mm}$ axial compression, which preceded the onset of collapse at $2.08 \mathrm{~mm}$ compression. The global FE model showed buckling of five to six half sine waves per stiffener bay from about $0.65 \mathrm{~mm}$ axial compression, where under further compression one or two half waves became dominant and showed larger deformation. There was continual change of the buckling shape until around $1.22 \mathrm{~mm}$ compression, at which point a stable and symmetric buckling pattern developed of three half waves per bay, as shown on the left in Figure 13, and this continued until the onset of fibre fracture in the stiffeners causing collapse. From the local model investigation, the critical skin-stiffener interface was at the panel centre, with interlaminar damage predicted at the stiffener flange edge in the centre stiffener bay.

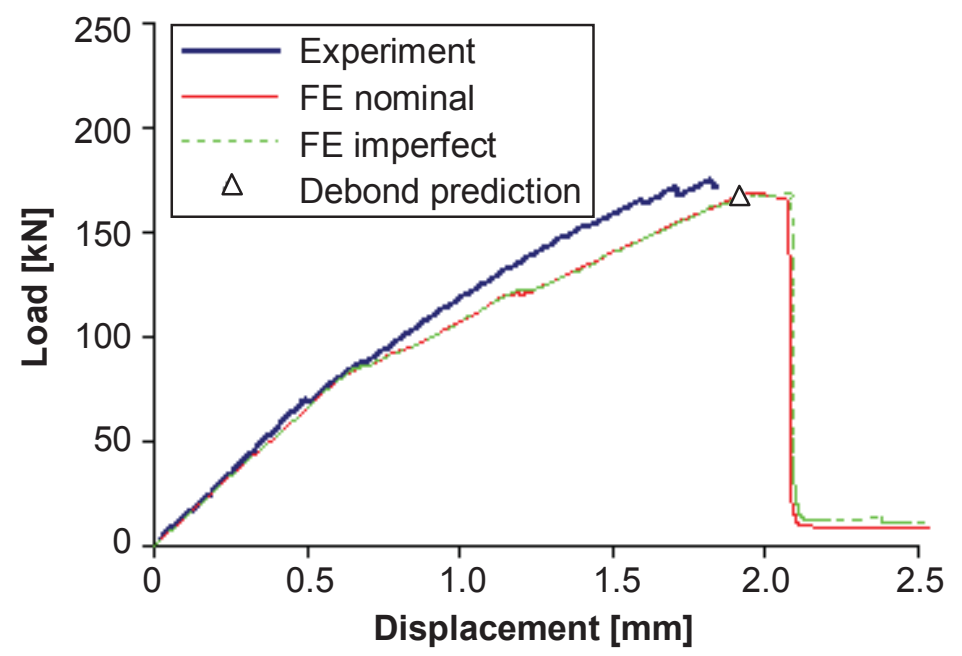

Figure 12: D2 panel, load-shortening and debond prediction, experiment and FE models. 

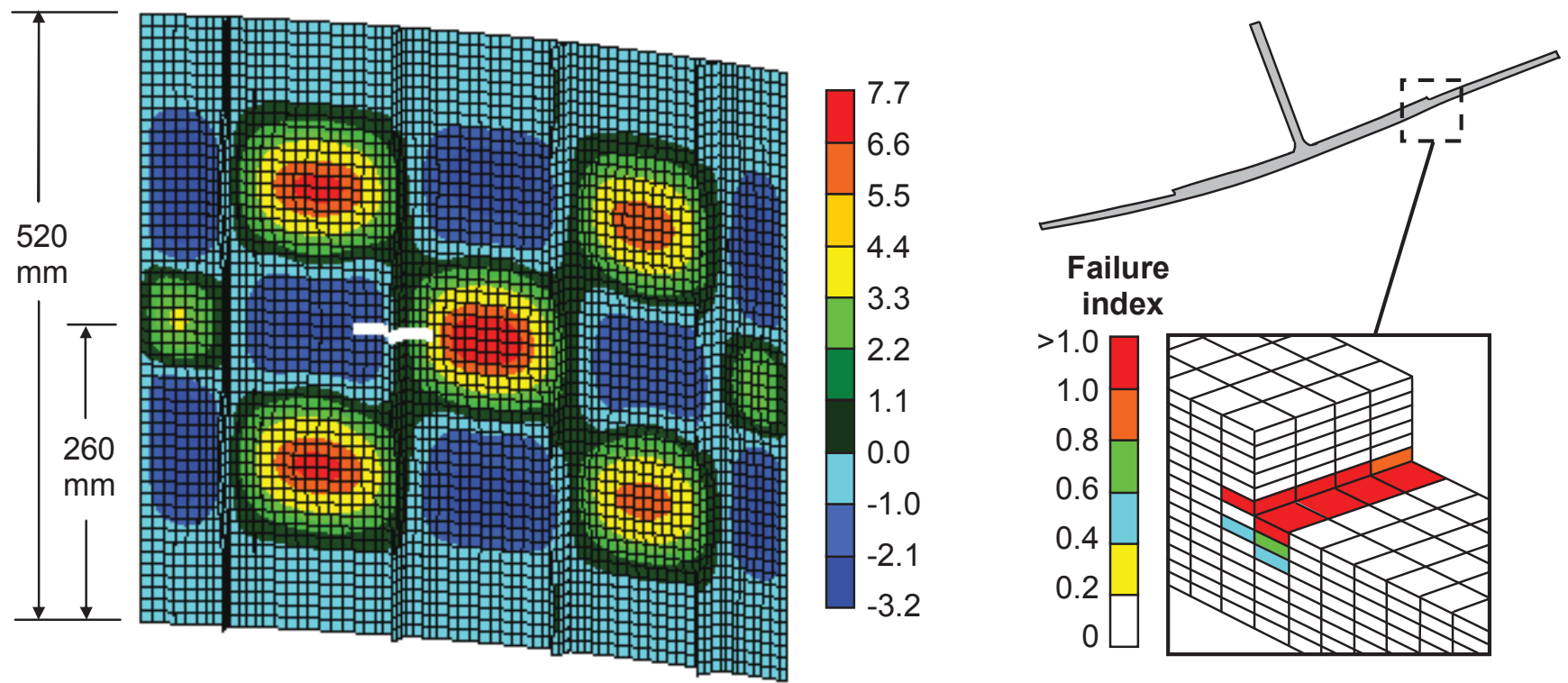

Figure 13: D2 panel at $1.92 \mathrm{~mm}$ axial displacement. Left: Global model radial displacement (in $\mathrm{mm}$ ) with local location shown. Right: Local model.

From the results, the nominal and imperfect models were almost identical, with the loaddisplacement, deformation pattern, and failure prediction all giving very similar results. In comparison with experiment, the global FE models were not able to predict the exact asymmetric buckling patterns seen experimentally, and the predicted structural stiffness was lower than the experimental value, particularly in the postbuckling region. In spite of this, the panel behaviour and onset of buckling were predicted well. The predicted initiation of debonding also compared very well with the experimental collapse of the panel, though the exact location of failure was not predicted as this was dependent on the deformation. However, investigation of local models at other locations revealed that the interlaminar damage was predicted to occur at multiple locations throughout the panel within a small range of compression values up to the point at which fibre fracture occurred. These locations included anti-nodal and nodal lines, where the anti-nodal lines such as that shown in Figure 13 gave failure at the flange edge due to high peel stresses, and the nodal lines of minimum displacement failed in the region underneath the stiffener due to high shear stresses.

\section{Pre-Damaged Panel (D1)}

The D1 panel was manufactured and inspected as previously described, with no damage found from the ultrasonic and thermographic scanning following manufacture. The measured imperfection data is given on the left in Figure 14, which as previously described corresponds to the radial displacement between the nominal and manufactured panel geometries. In testing, the panel was loaded with 2000 cycles up to $1.08 \mathrm{~mm}$ compression, 1700 cycles up to 1.93 mm compression, then statically until collapse. The cyclic loading corresponded to loads just before global buckling, and $95 \%$ of the expected displacement at collapse. Following an assessment of the results, it was seen that the cyclic loading, particularly the $95 \%$ loading, caused damage to occur in the panel that was considered as pre-damage for the final static loading to collapse. The experimental results are presented below, where the middle and right images in Figure 14 are thermographic and ultrasonic scans of the panel damage before and after the final static loading. For the final static loading, Figure 15 is the load-displacement curve with out-of-plane displacement fringes, and Figure 16 shows photographs of the panel during testing with out-of-plane-fringe images overlaid. 
Under loading the panel developed a local buckling pattern at around $0.75 \mathrm{~mm}$ axial compression of 13 to 15 longitudinal half waves per stiffener bay, leading to global buckling at around $1.0 \mathrm{~mm}$ axial compression. The global buckling pattern was symmetric and consisted of an inwards buckle (towards the stiffener side) located over the centre stiffener and outwards buckles in the outer stiffener bays. Under further compression the central buckle moved to one of the inner stiffener bays creating an asymmetric pattern.

In cyclic loading, periodic thermographic scans were used to monitor damage, and no damage was seen in the panel after the first 2000 cycles. After 400 cycles at the higher cyclic load, skin-stiffener debonding became evident at two locations in the centre and an inner stiffener. These areas were seen to grow under further cyclic loading, so that at 3700 cycles, when the cyclic loading was completed, the damage was as shown in the middle image of Figure 14. This corresponded to a debonded area of $2016 \mathrm{~mm}^{2}$ under the centre stiffener and $1920 \mathrm{~mm}^{2}$ under the inner stiffener, which were considered as the pre-damaged regions for the static loading.

Under static loading the same local and global buckling patterns seen in cyclic loading developed, though some opening of the debonded regions was evident by $2.5 \mathrm{~mm}$ axial compression. At around $2.5 \mathrm{~mm}$ axial compression the debonded areas showed a rapidly increased damage growth and opening displacement, which caused a large reduction in the load-carrying capacity of the panel, as seen in Figure 15. The damage growth process was seen again at around $2.81 \mathrm{~mm}$ axial compression, where growth of the debonded area led to an increase in the skin-stiffener opening, and also caused some fibre fracture and matrix cracking in the regions around the debonds. Collapse of the panel occurred at $3.31 \mathrm{~mm}$ axial compression and corresponded to significant fibre fracture through the centre stiffener.
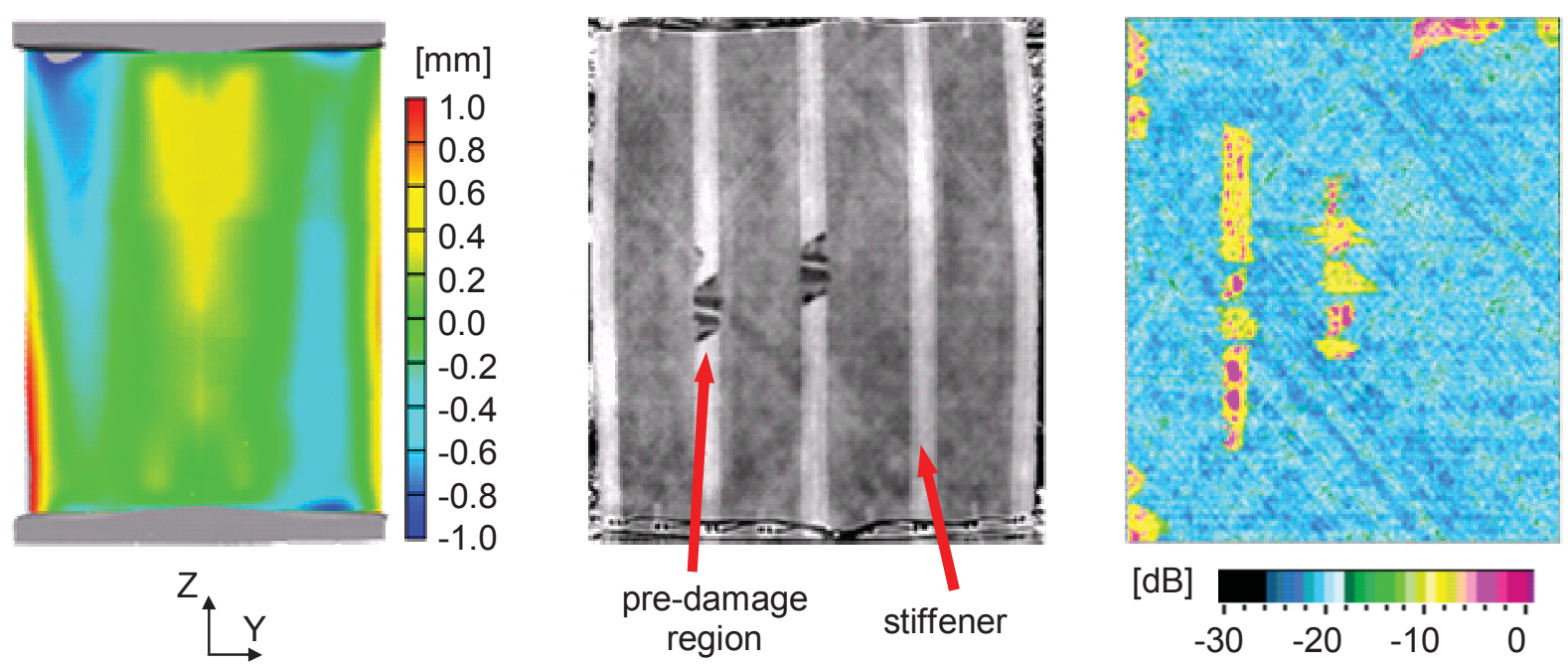

Figure 14: D1 panel. Left: Imperfection data. Middle: Thermography scan after 3700 cycles. Right: Ultrasonic scan after collapse (skin side) [30]. 


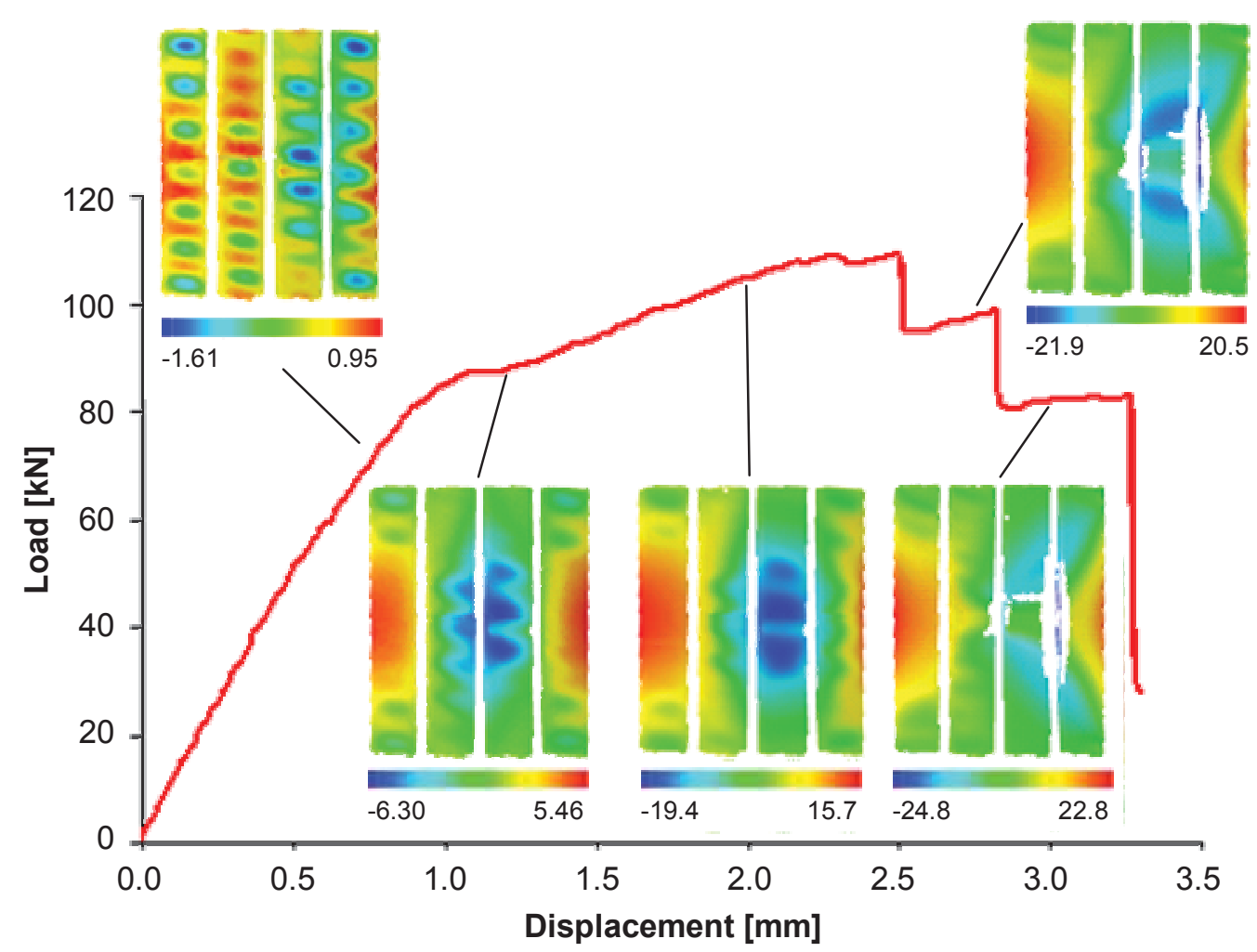

Figure 15: D1 experimental load-shortening, with radial displacement contours ( $\mathrm{mm}$ ) (stiffener side) [30].
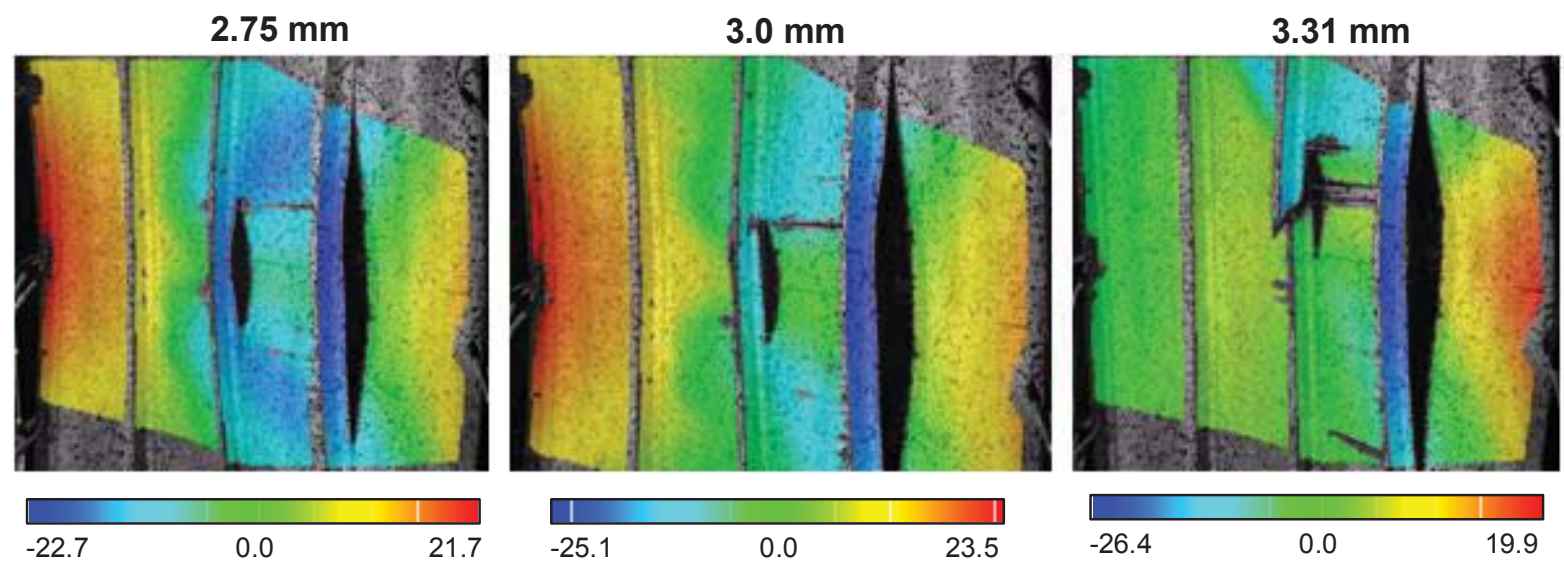

Figure 16: D1 test images with radial displacement contours ( $\mathrm{mm}$ ) at applied axial displacement.

In the numerical analysis, an FE model was created based on the analysis methodology described, and consisted of 6,004 nodes and 5,772 shell elements. The boundary conditions were similar to those shown for the D2 panel in Figure 9, though the longitudinal restraint was removed. Material properties for the model were the same as for the D1 panel and are given in Table 4. User-defined MPCs were included between the skin and stiffener of the centre and an inner stiffener, in order to model the debond growth seen in the experiment. Skin-stiffener debonds were created as pre-damage by setting the MPCs to the appropriate states. The pre-damaged debonded regions were taken from the thermographic scans of the damage, seen in Figure 14, and were adapted to the regular grid mesh of the model to most closely match the area and shape of the experimental damage sites, as shown in Figure 17. It was assumed that the cyclic loading only resulted in skin-stiffener debonding, and any other 
damage such as matrix cracking that could have been present in the panel prior to static loading was not considered.
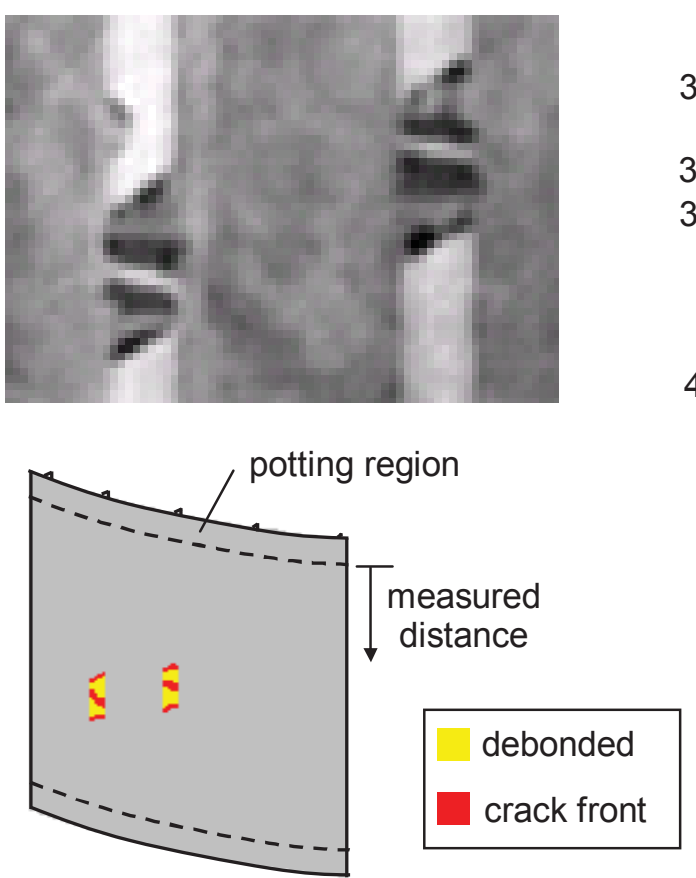
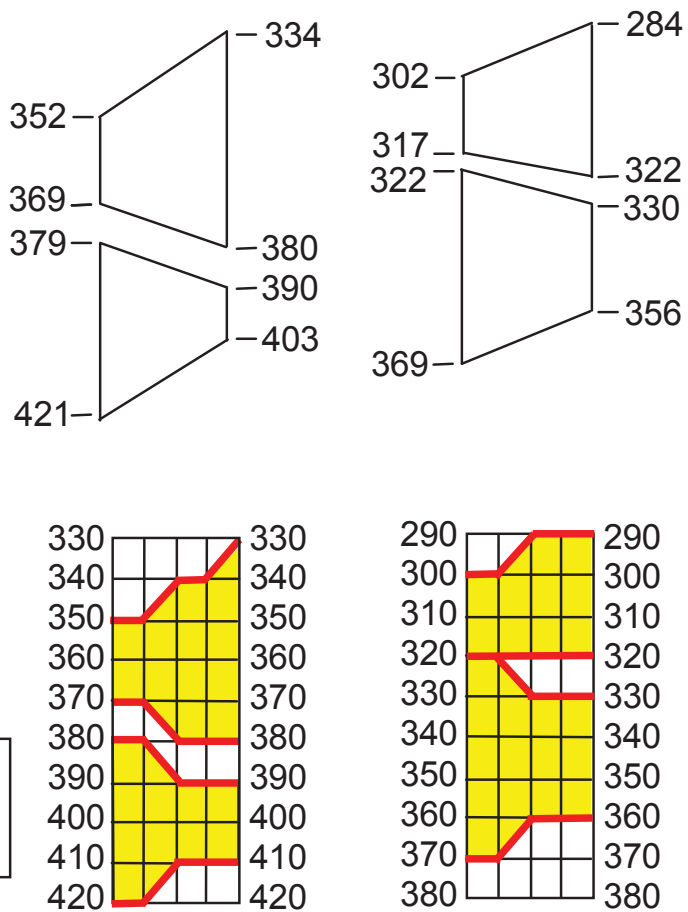

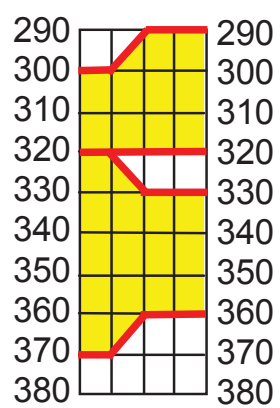

Figure 17: D1 cyclic test pre-damage. Top: Thermographic image and schematic representation. Bottom: FE approximation. Note distances given in mm to inside of potting on non-loading side.

The model was analysed in Marc v2005r3 using the nonlinear solver with a full NewtonRaphson procedure and a load residuals tolerance of 0.01 . The results are given below, where Figure 18 is the load response with the length of the debonded areas under the centre and offcentre stiffener also shown. The lengths of the debonded areas were calculated using the average debond edge locations based on nodal coordinates. As the initial pre-damaged configuration consisted of two separate debond regions under the two stiffeners, shown in Figure 17, the average of the two regions was used as the debond length. Figure 19 gives the out-of-plane deformation, Figure 20 illustrates the debond growth, and Figure 21 gives the failure index and out-of-plane displacement in the final deformed configuration, where gap elements can be seen across the debonded skin-stiffener interfaces. 


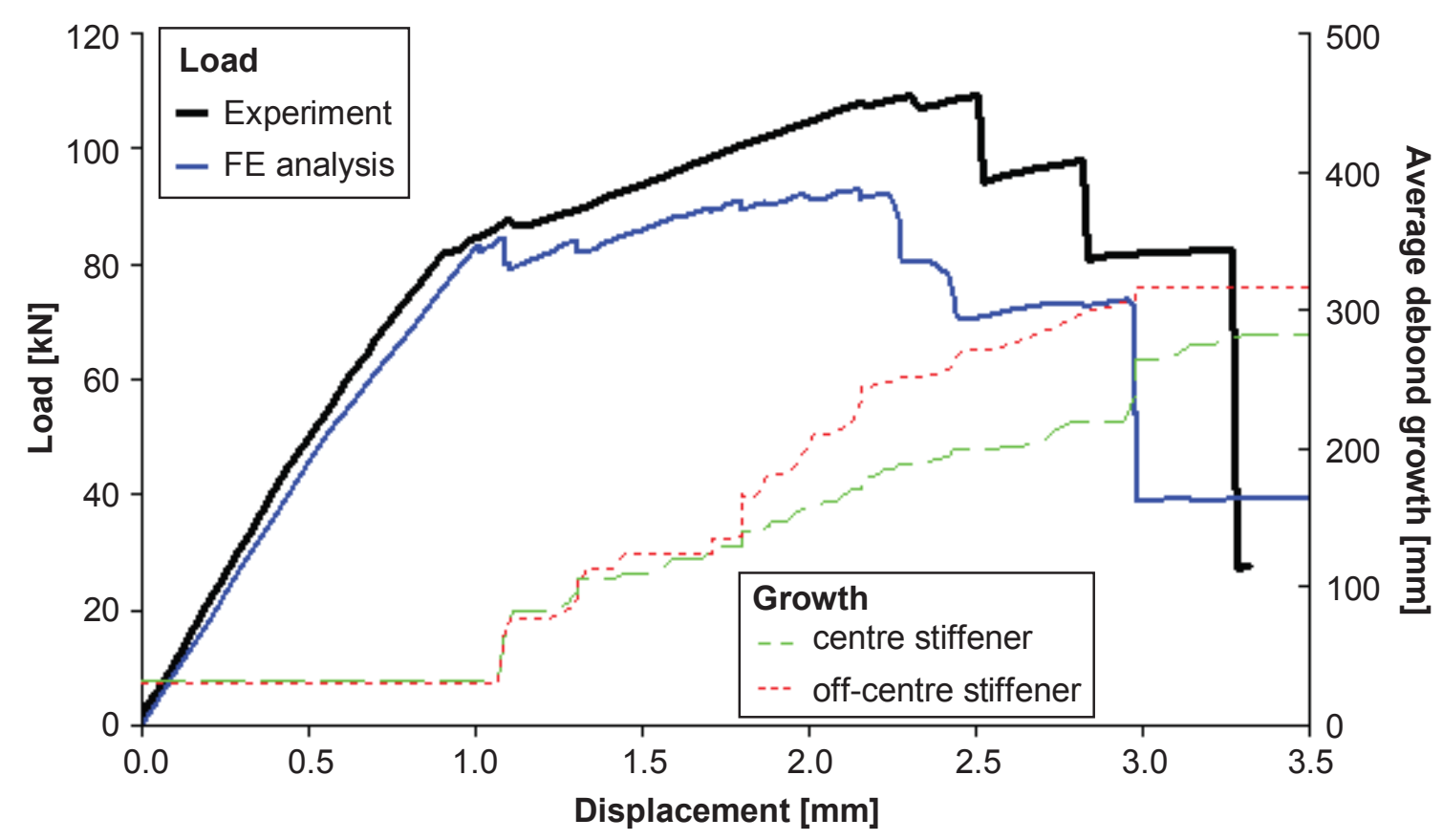

Figure 18: D1 panel, experimental and numerical load-displacement curves, and debond lengths under the centre and off-centre stiffeners in the numerical model.
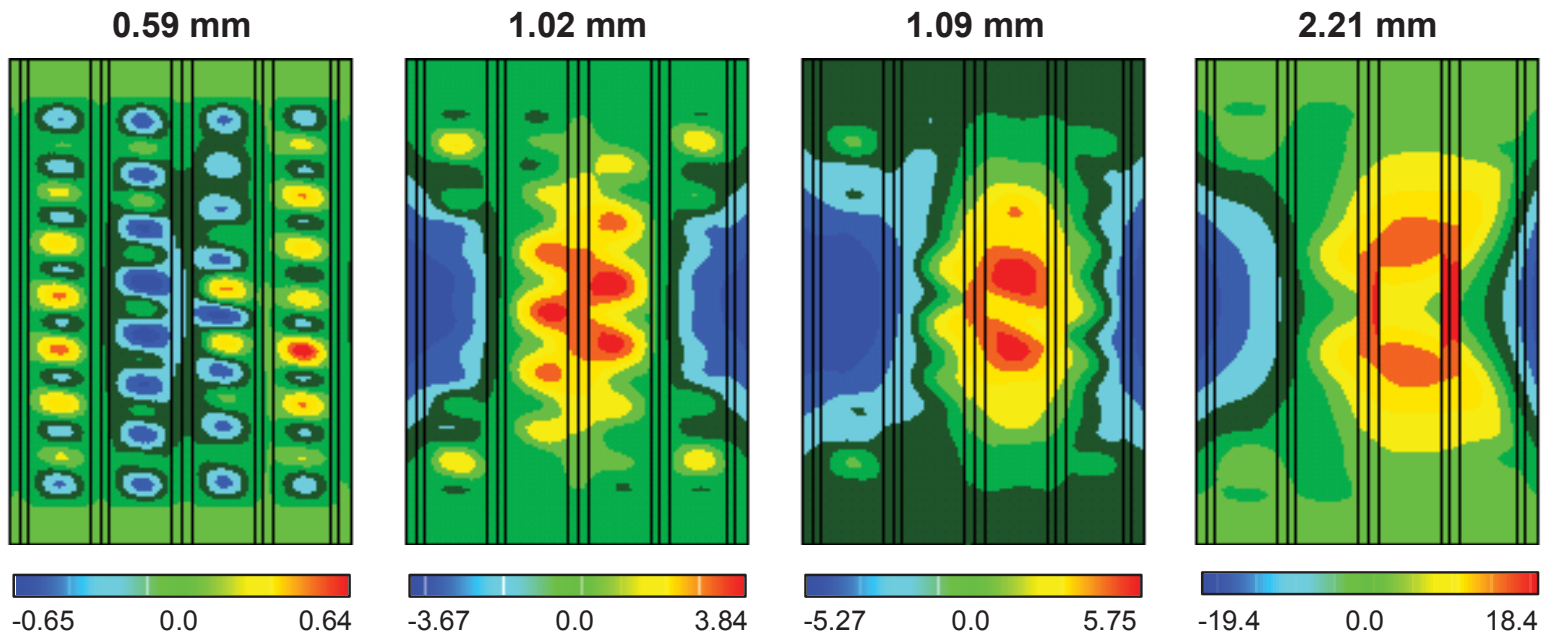

Figure 19: D1 panel, out-of-plane deformation (mm) (stiffener side) at applied axial compression. 


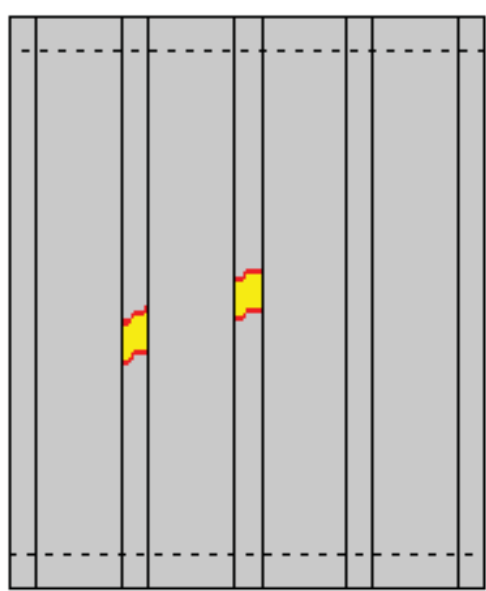

$1.09 \mathrm{~mm}$

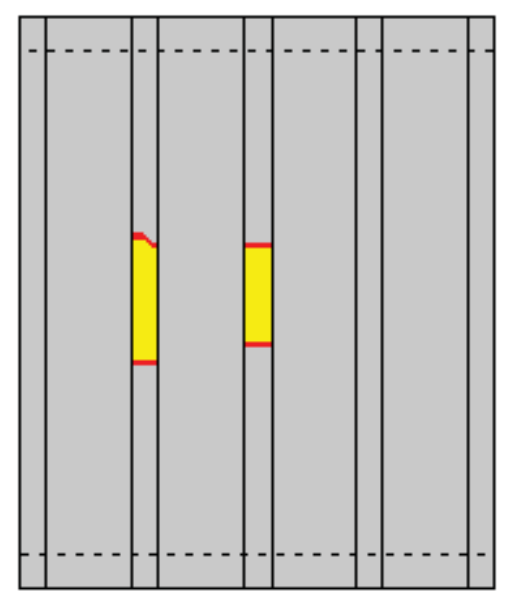

$1.8 \mathrm{~mm}$

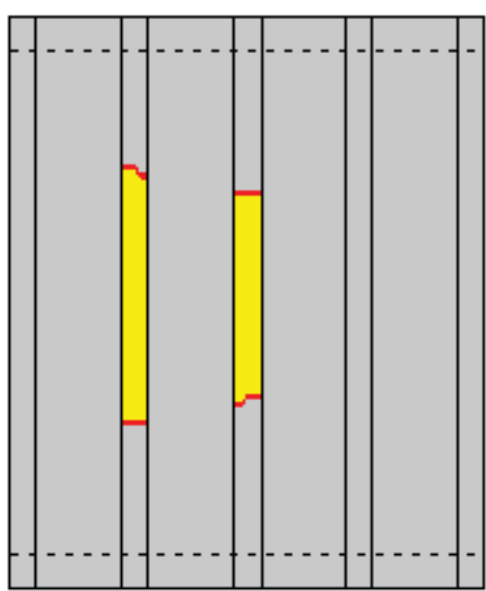

$2.98 \mathrm{~mm}$

Figure 20: D1 panel, debonded area at applied displacement (skin side).
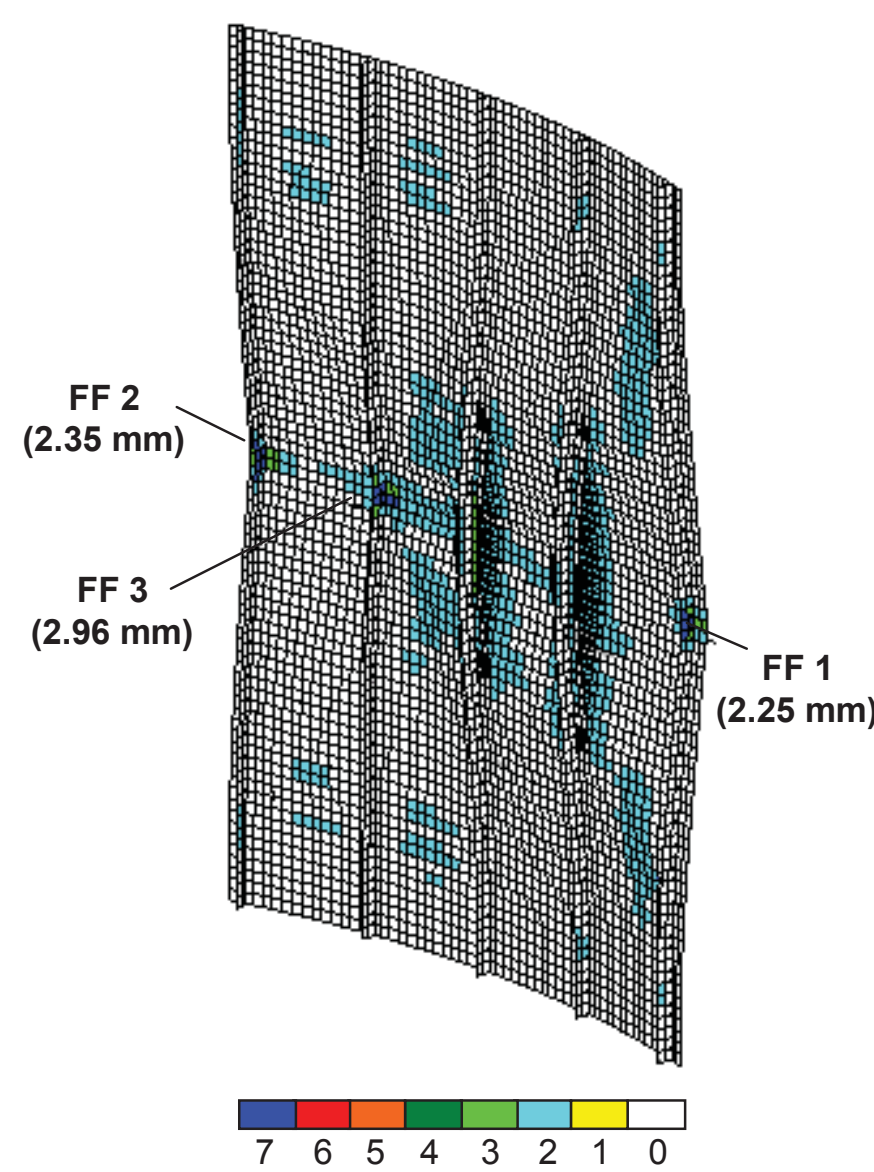

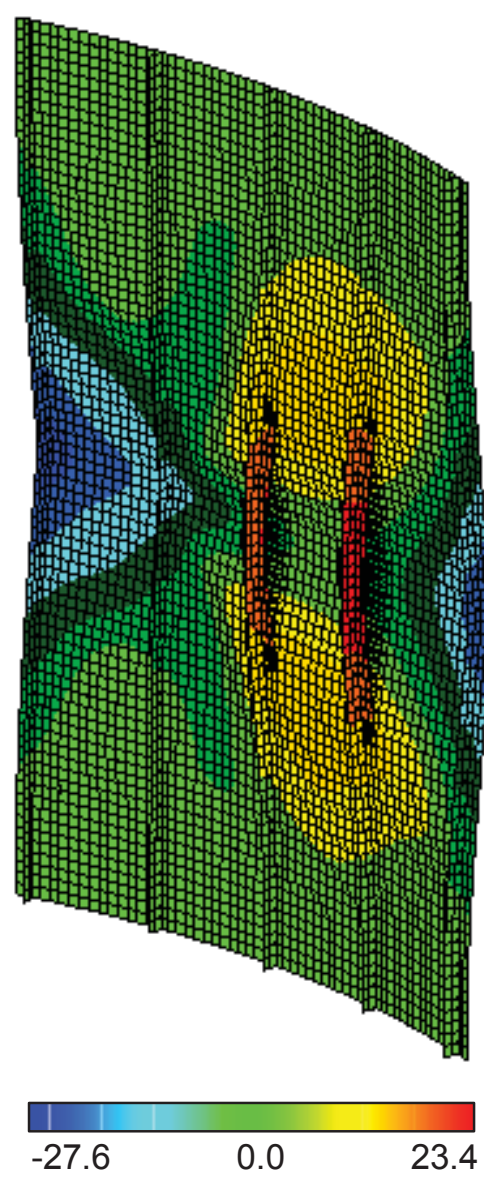

Figure 21: D1 panel at $2.98 \mathrm{~mm}$ applied displacement (collapse). Left: Ply failure index showing stiffener fibre failure (FF) sequence. Right: Out-of-plane deformation (mm).

From Figure 19, the FE model gave a local buckling pattern of 15 half waves per bay and global buckling of a single central buckle at $1.02 \mathrm{~mm}$ compression that moved to be located between two inner stiffeners by $1.09 \mathrm{~mm}$ compression. This behaviour agreed very well with the experimental behaviour shown in Figure 15. The buckling behaviour can also be observed in Figure 18 from drops in the load curve and changes in the panel stiffness. In the numerical model, the movement of the global buckle coincided with coalescence of the separate debonded regions under the two stiffeners, and some opening was seen across these interfaces. 
This can be seen in the left image of Figure 20. Growth of the debonded regions was then predicted to occur in a continuous manner, and was characterised by drops in the load response and increased skin-stiffener opening. This behaviour is shown in load and crack growth data in Figure 18, and is also illustrated at various stages in Figure 20. Crack growth was accompanied by matrix cracking in mainly the outer $90^{\circ}$ plies of the skin, which was focused on the centre and edges of the debonded regions. Though correspondence was not seen at all predicted locations, the experimental panel did show matrix cracking in the outer plies extending from the skin-stiffener debond edges.

Under further compression, the numerical model showed fibre fracture in mainly the central $0^{\circ}$ stiffener plies at $2.25 \mathrm{~mm}, 2.35 \mathrm{~mm}$ and $2.96 \mathrm{~mm}$ axial compression, with the two outer stiffeners and an inner stiffener failing sequentially as shown on the left in Figure 21. Fibre fracture was characterised by large drops in the load response of the panel of around $10 \mathrm{kN}$ for the outer stiffener failures, and around $30 \mathrm{kN}$ for the inner stiffener, where the latter was taken as the collapse of the panel. Though the experimental panel showed failure in the central stiffener causing collapse, the sequence and size of the load reductions, the onset of fibre fracture in the central $0^{\circ}$ plies of the stiffeners, and the way in which the debond growth and matrix cracking contributed to fibre fracture and panel collapse all closely matched the experimental results.

Whilst it was difficult to extract precise crack growth data from the experimental results, crack opening was seen at several stages before and after fibre fracture, and the experimental debonded area under the inner stiffener showed greater crack growth. Both of these aspects were seen in the numerical model, and in general the crack growth behaviour illustrated in Figure 20 compares well with the experimental results. Additionally, the approximate final debonded lengths of the experimental panel were $224 \mathrm{~mm}$ and $403 \mathrm{~mm}$ under the central and inner stiffener respectively, which gave very good comparison with the numerical values of $282 \mathrm{~mm}$ and $316 \mathrm{~mm}$, especially considering the fact that fibre fracture in the experimental panel would have caused additional crack growth and energy released.

\section{DISCUSSION}

For the intact panels, the use of the strength-based criterion averaged within a ply element was seen to give accurate predictions for the initiation of delamination. However, strengthbased failure prediction at stress singularities such the stiffener flange edges are known to be mesh-dependent. As such, the failure predictions in this work are equivalent to the point stress or average stress approaches [32], and require calibration of the mesh size. The mesh size used in this work was taken from previous studies investigating interlaminar damage initiation in local skin-stiffener interfaces under postbuckling deformations [911-12]. An alternative approach is to apply interface elements based on continuum damage mechanics to capture interlaminar crack growth [24]. This approach, although requiring careful selection of the mesh size in consideration of the process zone, eliminates the need for mesh size calibration [33].

The strength-based failure criterion applied in this work used ply stresses to predict an interlaminar failure. This approach is commonly applied by researchers, such as those covered by the review articles of References [34-35]. Alternative approaches include investigating stresses at the ply interfaces such as with an interface element, or accounting for the difference in ply angles at each interface [36-37]. In a similar manner, the ply failure degradation model of Chang and Lessard [20] applied in this work is known to be meshdependent, due to the localisation of damage [33]. This effect can be mitigated by using a 
calibrated mesh size that properly accounts for the energy dissipation, or by incorporating a crack band model based on a characteristic element length [38-40].

For the crack growth analyses, the nature of the secondary bonded skin-stiffener interface is the most critical factor affecting the comparison with the experimental results. As previously mentioned, all of the fracture toughness properties were determined from investigations of a $0^{\circ}-0^{\circ}$ ply-ply interface, and though the assumption of analogous behaviour in the plyadhesive-ply interface is necessary, the accuracy of this assumption in general remains largely unknown. In particular, this uncertainty is not only relevant for the fracture toughness values, but also for the law governing mixed-mode behaviour and the mixed-mode parameters. Additionally, it must be remembered that there is considerable uncertainty associated with fracture toughness values in general, where a large amount of variance is typically seen in experimentally determined values, particularly in mode II and mixed-mode I-II tests. Though very good agreement was seen in the crack growth predictions, it is important to recognise that these predictions are dependent on parameters that are themselves difficult to determine.

For all analyses, there were a number of factors that considerably influenced comparison with experimental results. One aspect was the difficulty in accurately capturing the correct buckling mode shapes and deformation patterns, which was especially critical for crack growth in the region just ahead of any crack front. Also, the influence of mesh density remains significant for any analysis, where though the effect on strength-based failure predictions was uncertain, using smaller elements would have led to reduced strain energy release rates and less conservative predictions in all crack growth analyses. Separately, for the comparison with the cyclically-loaded experimental panel, the effect of the repeated loading into deep postbuckling on the integrity of the panel and general structural behaviour remains largely uncertain. In spite of these aspects, the developed approach allowed for in-depth analysis of the critical damage mechanisms, and was able to illustrate the way in which these mechanisms combined to produce final panel collapse.

One aspect that remains important in the application of the developed approach for both design and analysis is the computation time. For the analysis presented, computation times were dependent on the extent of crack growth and fibre fracture, and range from 40 minutes to more than a week for models where these factors were significant. In general, this order of computation time fits in with the aims of the developed approach to form part of a necessarily "slow" analysis tool suitable for aircraft certification. A more efficient process would obviously be desirable, and can be achieved in a number of ways, including increasing the efficiency of the subroutine code, using a less severe knockdown of properties in ply softening, and applying the degradation models to selected regions only. However, it must be remembered that accurate analysis of crack growth and ply failure requires fine detail modelling and significant computational expense, and that experience is required to apply any damage model within a practical design and analysis procedure.

Overall, results presented demonstrated the capability of the developed approach to provide accurate predictions of the behaviour of postbuckling composite stiffened panels, and critically to capture the damage mechanisms for compression loading. The methodology has application for the design and analysis of the next generation of aircraft structures, as it allows for the significant efficiency gains from postbuckling design to be applied with composite materials.

\section{CONCLUSIONS}


In this work an analysis methodology for capturing the critical damage mechanisms leading to collapse in composite stiffened structures was proposed. One aspect of the methodology was a global-local analysis technique that monitored a strength criterion in cross-section models to predict the initiation of interlaminar damage in intact structures. A degradation model was developed for capturing in-plane ply damage due to fibre fracture, matrix cracking and fibrematrix shear that was based on the criteria of Hashin [15] and property reduction method of Chang and Lessard [20]. A separate degradation model was developed for representing crack growth in the skin-stiffener interface in which user-defined MPCs are controlled using the VCCT. All approaches were implemented into the nonlinear analysis solver of Marc v2005r3 using a combination of user subroutines.

Experimental results were presented for fuselage-representative composite panels loaded in compression to collapse, in both intact and pre-damaged configurations. For the intact panel, failure occurred in the postbuckling region due to the onset of skin-stiffener debonds and delaminations, which led to catastrophic collapse. For the pre-damaged panel, skin-stiffener debond regions were created by first loading the panel cyclically into the postbuckling region. Upon final static compression to collapse, the skin-stiffener pre-damage regions grew, and led to sequential failure in the panel stiffeners. For both intact and pre-damaged panels, the analysis methodology was able to successfully capture the specimen behaviour and critical damage mechanisms, and gave realistic predictions of the panel collapse. The application of the methodology in this manner allows the strength reserve of postbuckling composite design to be exploited, which has application for the next generation of composite aerospace structures.

\section{ACKNOWLEDGMENTS}

This research is part of the Research Program of the Cooperative Research Centre for Advanced Composite Structures (CRC-ACS) Ltd. The authors kindly acknowledge the financial support of: the Australian Postgraduate Awards Scheme; the Cooperative Research Centre for Advanced Composite Structures (CRC-ACS); the German Academic Exchange Service, the Italian Ministry of Foreign Affairs; the Australian Government under both the "Innovation Access Programme - International Science and Technology" and "International Science Linkages" established under the Australian Government's innovation statement, "Backing Australia's Ability". The work of the experimental testing staff at the Institute of Composite Structures and Adaptive Systems at DLR Braunschweig is also gratefully acknowledged. COCOMAT is supported by the European Commission, Priority Aeronautics and Space, Contract AST3-CT-2003-502723.

\section{REFERENCES}

1. Degenhardt, R., Rolfes, R., Zimmerman, R. and Rohwer, K. (2006). COCOMAT Improved MATerial Exploitation at Safe Design of COmposite Airframe Structures by Accurate Simulation of COllapse. Composite Structures, 73: 178-178.

2. COCOMAT Home Page. (2008). www.cocomat.de

3. Zimmermann, Z., Klein, H. and Kling, A. (2006). Buckling and postbuckling of stringer stiffened fibre composite curved panels - tests and computations. Composite Structures, 73: 150-161.

4. Abramovich, H., Grunwald, A., Pevsner, P., Weller, T., David, A., Ghilai, G., Green, A. and Pekker, N. (2003). Experiments on axial compression postbuckling behavior of stiffened cylindrical composite panels. 44th AIAA/ASME/ASCE/AHS Structures, 
Structural Dynamics and Materials Conference, Norfolk, VI, USA, AIAA paper no. 2003-1893.

5. Greenhalgh, E.S., Meeks, C., Clarke, A. and Thatcher, J. (2003). The effect of defects on the performance of post-buckled CFRP stringer-stiffened panels. Composites: Part A, 34: 623-633.

6. MSC.Marc and MSC.Mentat User Manuals Version $2005 r 3$ (2006), MSC.Software Corporation, Santa Ana, California.

7. Orifici, A.C. (2007). Degradation Models for the Collapse Analysis of Composite Aerospace Structures. PhD thesis, Royal Melbourne Institute of Technology.

8. Orifici, A.C., Thomson, R.S., Degenhardt, R., Bisagni, C. and Bayandor, J. (2009). An analysis tool for design and certification of postbuckling composite aerospace structures. International Journal of Structural Stability and Dynamics. (to appear).

9. Orifici, A.C., Thomson, R.S., Herszberg, I., Weller, T., Degenhardt, R. and Bayandor, J. (2008). An analysis methodology for failure in postbuckling skin-stiffener interfaces. Composite Structures, 86: 186-193.

10. Tong, T. (1997). An assessment of failure criteria to predict the strength of adhesively bonded double lap joints. Journal of Reinforced Plastics and Composites, 16: 698-715.

11. Orifici, A.C., Herszberg, I., Thomson, R.S., Weller, T., Kotler, A. and Bayandor, J. (2007). Failure in stringer interfaces in postbuckled composite stiffened panels. 12th Australian International Aerospace Congress, Melbourne, Australia, 19-22 March.

12. Orifici, A.C., Shah, S.A., Herszberg, I., Kotler, A. and Weller, T. (2008). Failure analysis in postbuckled composite T-sections, Composite Structures, 86: 146-153.

13. Tsai, S.W. and Wu, E.M. (1971). A general theory of strength for anisotropic material, Journal of Composite Materials, 5: 58-80.

14. Hinton, M.J., Kaddour, A.S. and Soden, P.D. (2004). Failure Criteria in FibreReinforced-Polymer Composites, Elsevier, The Netherlands.

15. Hashin, Z. (1980). Failure criteria for unidirectional composites. Journal of Applied Mechanics, 47: 329-334.

16. Puck, A. and Schürmann, H. (1998). Failure analysis of FRP laminates by means of physically based phenomenological models, Composites Science and Technology, 58: 1045-1067.

17. Cuntze, R.G. and Freund, A. (2004). The predictive capability of failure mode concept-based strength criteria for multidirectional laminates, Composites Science and Technology, 64: 344-377.

18. Camanho, P.P., Dávila, C.G., Pinho, S.T., Iannucci, L. and Robinson, P. (2006). Prediction of in situ strengths and matrix cracking in composites under transverse tension and in-plane shear. Composites Part A, 37: 165-176.

19. Ambur, D.R., Jaunky, N. and Hilburger, M.W. (2004). Progressive failure studies of stiffened panels subjected to shear loading. Composite Structures, 65: 129-142.

20. Chang, F.K. and Lessard, L.B. (1991). Damage tolerance of laminated composites containing an open hole and subject to compressive loadings: part I - analysis. Journal of Composite Materials, 25: 2-43.

21. Orifici, A.C., Thomson, R.S., Degenhardt, R., Bisagni, C. and Bayandor, J. (2007). Development of a finite element methodology for the propagation of delaminations in composite structures. Mechanics of Composite Materials, 43(1): 9-28.

22. Orifici, A.C., Thomson, R.S., Degenhardt, R., Büsing, S. and Bayandor, J. (2007). Development of a finite element methodology for modelling mixed-mode delamination growth in composite structures. 12th Australian International Aerospace Congress, Melbourne, Australia, 19-22 March. 
23. Rybicki, E.F. and Kanninen, M.F. (1977). A finite element calculation of stress intensity factors by a modified crack closure integral. Engineering Fracture Mechanics, 9: 931-938.

24. Krueger, R. (2004). Virtual crack closure technique: History, approach and applications. Applied Mechanics Review, 57(2): 109-143.

25. Benzeggagh, M.L. and Kenane, M. (1996). Measurement of mixed-mode delamination fracture toughness of unidirectional glass/epoxy composites with mixedmode bending apparatus. Composites Science and Technology, 56: 439-449.

26. Camanho, P.P. and Dávila, C.G. (2003). Numerical simulation of mixed-mode progressive delamination in composite materials, Journal of Composite Materials, $\mathbf{3 7}$ : 1415-1438.

27. Davidson, B.D, Krüger, R. and König, M. (1996). Effect of stacking sequence on energy release rate distributions in multidirectional DCB and ENF specimens, Engineering Fracture Mechanics, 55(4): 557-569.

28. Andersons, J. and König, M. (2004). Dependence of fracture toughness of composite laminates on interface ply orientations and delamination growth direction, Composites Science and Technology, 64: 2139-2152.

29. www.gom.com

30. Degenhardt, R., Kling, A., Klein, H., Hillger, W., Goetting, H.C., Zimmermann, R., Rohwer, K. and Gleiter, A. (2007). Experiments on buckling and postbuckling of thinwalled CFRP structures using advanced measurement systems. International Journal of Structural Stability and Dynamics, 7(2): 337-358.

31. Hansen P., Martin R. DCB, $4 E N F$ and $M M B$ delamination characterisation of S2/8552 and IM7/8552. Materials Engineering Research Laboratory Ltd. (MERL), Hertford, UK, N68171-98-M-5177; 1999.

32. Whitney J.M. and Nuismer, R.J. (1974) Stress fracture criteria for laminated composites containing stress concentrations. Journal of Composite Materials, 8:25365.

33. Camanho, P.P., Maimí, P. and Dávila, C.G. (2007) Prediction of size effects in notched laminates using continuum damage mechanics. Composites Science and Technology, 67: 2715-27.

34. Orifici, A.C., Herszberg, I. and Thomson, R.S. (2008). Review of methodologies for composite material modelling incorporating failure. Composite Structures, 86: 165-76.

35. D’Ottavio, M. and König, M. (2006). Numerical models for delamination. In: Busse, G., Kröplin, B.-H. and Wittel, F.K. (eds) Damage and its evolution in fiber-composite materials: Simulation and non-destructive testing, Stuttgart University: ISD Verlag, 381-424.

36. Chai, Y. (1996). A Finite Element Method for Predicting Impact Damage in Composite Stiffened-Panels. Master degree dissertation, North-Western Polytechnical University (NPU).

37. Chai, Y. and Gädke, M. (1999). Impact damage simulation and compression after impact of composite stiffened panels. IB 131-99/20, DLR Braunschweig.

38. Bažant, Z.P. and Oh, B.H. Crack band theory for fracture of concrete. (1983). Mater Construc. 16(93): 155-77.

39. Bažant, Z.P. and Jirásek, M. (2002). Nonlocal integral formulations of plasticity and damage: survey of progress. J Eng Mech. 128: 1119-49.

40. Lapczyk I. and Hurtado J.A. (2007). Progressive damage modelling in fiber-reinforced materials. Composites - Part A. 38: 2333-41. 
Manuscript for Journal of Composite Materials, submitted June 2008, revised Jan 2009 


\section{TABLES}

Table 1: In-plane failure criteria and property reduction.

\begin{tabular}{lll}
\hline Failure type & Criterion & Properties reduced \\
\hline Fibre, tension & $\left(\sigma_{11}^{2} / X_{T}^{2}\right)^{\frac{1}{2}} \geq 1$ & $\begin{array}{l}E_{11}, E_{22} \\
G_{12}, G_{23}, G_{31}\end{array}$ \\
Fibre, compression & $\left(\sigma_{11}^{2} / X_{C}^{2}\right)^{\frac{1}{2}} \geq 1$ & \\
\hline Matrix, tension & $\left(\sigma_{22}^{2} / Y_{T}^{2}+\tau_{12}^{2} / S_{12}^{2}\right)^{\frac{1}{2}} \geq 1$ & \\
Matrix, compression & $\left(\frac{\sigma_{22}}{Y_{C}}\left(\frac{Y_{C}{ }^{2}}{4 S_{23}^{2}}-1\right)+\frac{\sigma_{22}^{2}}{4 S_{23}^{2}}+\frac{\sigma_{12}^{2}}{4 S_{12}^{2}}\right)^{\frac{1}{2}} \geq 1$ & $E_{22}$ \\
\hline $\begin{array}{l}\text { Fibre-matrix shear, tension } \\
\begin{array}{l}\text { Fibre-matrix shear, } \\
\text { compression }\end{array}\end{array}$ & $\left(\sigma_{12}^{2} / S_{12}^{2}\right)^{\frac{1}{2}} \geq 1$ & $G_{12}, G_{31}$ \\
\hline
\end{tabular}


Table 2: Combined failure index for in-plane ply failure.

\begin{tabular}{llllc}
\hline Failure & $\boldsymbol{f}$ & $\boldsymbol{m}$ & $\boldsymbol{s}$ & Index \\
\hline no failure & 0 & 0 & 0 & 0 \\
fibre-matrix shear & 0 & 0 & 1 & 1 \\
matrix & 0 & 1 & 0 & 2 \\
matrix + fibre-matrix shear & 0 & 1 & 1 & 3 \\
fibre & 1 & 0 & 0 & 4 \\
fibre + fibre-matrix shear & 1 & 0 & 1 & 5 \\
fibre + matrix & 1 & 1 & 0 & 6 \\
fibre + matrix + fibre-matrix shear & 1 & 1 & 1 & 7 \\
\hline
\end{tabular}


Table 3: Nominal D1 and D2 panel details, all dimensions in mm.

\begin{tabular}{lll}
\hline Parameter & D1 & D2 \\
\hline Number of stiffeners & 5 & 4 \\
Total length, $L$ & 780 & 520 \\
Free length, $L_{f}$ & 620 & 400 \\
Arc length, $W$ & 560 & 624 \\
Radius, $R$ & 1000 & 1000 \\
Stiffener pitch, $b$ & 132 & 156 \\
Skin lay-up & {$[90, \pm 45,0]_{\mathrm{S}}$} & {$[ \pm 45,0,90]_{\mathrm{S}}$} \\
Stiffener lay-up & {$\left[( \pm 45)_{3}, 0_{6}\right]_{\mathrm{S}}$} & {$\left[ \pm 45,0_{2}, 90_{2}\right]_{\mathrm{S}}$} \\
Ply material & $\mathrm{IM} 7 / 8552, \mathrm{UD}$ & $\mathrm{IM} 7 / 8552, \mathrm{UD}$ \\
Adhesive & $\mathrm{FM} 300$ & $\mathrm{FM} 300$ \\
Ply thickness, $t$ & 0.125 & 0.152 \\
Stiffener height, $h$ & 14 & 28.9 \\
Stiffener width, $w$ & 32 & 56 \\
\hline
\end{tabular}


Table 4: Material properties for IM7/8552 carbon/epoxy unidirectional tape.

\begin{tabular}{llll}
\hline Stiffness property & Value & Fracture property & Value \\
\hline$E_{11}[\mathrm{GPa}]$ & 147 & $G_{\mathrm{Ic}}\left[\mathrm{kJ} / \mathrm{m}^{2}\right]$ & 0.243 \\
$E_{22}[\mathrm{GPa}]$ & 11.8 & $G_{\mathrm{II}}\left[\mathrm{kJ} / \mathrm{m}^{2}\right]$ & 0.514 \\
$v_{12}$ & 0.3 & $G_{\mathrm{III} \mathrm{c}}{ }^{*}\left[\mathrm{~kJ} / \mathrm{m}^{2}\right]$ & 0.514 \\
$G_{12}[\mathrm{GPa}]$ & 6.0 & $\mathrm{~B}-\mathrm{K}$ coefficient, $\eta^{*}$ & 4.6 \\
$G_{23}[\mathrm{GPa}]$ & 4.0 & & \\
$G_{31}$ * $[\mathrm{GPa}]$ & 6.0 & & \\
\hline *assumed & & &
\end{tabular}

